\title{
Intercomparison of the representations of the atmospheric chemistry of pre-industrial methane and ozone in earth system and other global chemistry-transport models
}

\author{
Richard G. Derwent $^{\text {a, }}$, David D. Parrish ${ }^{\mathrm{b}}$, Alex T. Archibald ${ }^{\mathrm{c}, \mathrm{d}}$, Makoto Deushi ${ }^{\mathrm{e}}$, \\ Susanne E. Bauer ${ }^{\mathrm{f}, \mathrm{g}}$, Kostas Tsigaridis ${ }^{\mathrm{g}, \mathrm{f}}$, Drew Shindell ${ }^{\mathrm{h}}$, Larry W. Horowitz ${ }^{\mathrm{i}}$, \\ M. Anwar H. Khan ${ }^{\mathrm{j}}$, Dudley E. Shallcross ${ }^{\mathrm{j}, \mathrm{k}}$ \\ ${ }^{a}$ rdscientific, Newbury, Berkshire, RG14 6LH, United Kingdom \\ ${ }^{\mathrm{b}}$ David D. Parrish, LLC, Boulder, CO, USA \\ ${ }^{\mathrm{c}}$ Department of Chemistry, University of Cambridge, Lensfield Road, Cambridge, CB2 1EW, UK \\ ${ }^{\mathrm{d}}$ National Centre for Atmospheric Science, UK \\ ${ }^{\mathrm{e}}$ Meteorological Research Institute, Japan Meteorological Agency, Tsukuba, Japan \\ ${ }^{\mathrm{f}}$ NASA Goddard Institute for Space Studies, New York, USA \\ ${ }^{g}$ Center for Climate Systems Research, Columbia University, New York, USA \\ ${ }^{\mathrm{h}}$ Nicholas School of the Environment, Duke University, Durham, NC, 27708, USA \\ ${ }^{i}$ NOAA Geophysical Fluid Dynamics Laboratory, Princeton, NJ, USA \\ ${ }^{\mathrm{j}}$ Biogeochemistry Research Centre, School of Chemistry, University of Bristol, Cantock's Close, Bristol BS8 1TS, UK \\ ${ }^{\mathrm{k}}$ Department of Chemistry, University of Western Cape, Robert Sobukwe Road, Bellville, 7375, South Africa
}

\section{H I G H L I G H T S}

- Eight chemical mechanisms are carefully examined for pre-industrial times.

- Inter-mechanism differences stem from representation of $\mathrm{C}_{1}-\mathrm{C}_{3}$ chemistry.

- Intra-mechanism ranges are wider than inter-mechanism ranges.

\section{A B S T R A C T}

An intercomparison has been set up to study the representation of the atmospheric chemistry of the pre-industrial troposphere in earth system and other global tropospheric chemistry-transport models. The intercomparison employed a constrained box model and utilised tropospheric trace gas composition data for the preindustrial times at ninety mid-latitude surface locations. Incremental additions of four organic compounds: methane, ethane, acetone and propane, were used to perturb the constrained box model and generate responses in hydroxyl radicals and tropospheric ozone at each location and with each chemical mechanism. Although the responses agreed well across the chemical mechanisms from the selected earth system and other global tropospheric chemistry-transport models, there were differences in the detailed responses between the chemical mechanisms that could be tracked down by sensitivity analysis to differences in the representation of $\mathrm{C}_{1}-\mathrm{C}_{3}$ chemistry. Inter-mechanism ranges in $\mathrm{NO}_{\mathrm{x}}$ compensation points were about $0.17 \pm 0.12$ when expressed relative to the inter-mechanism average. Monte Carlo uncertainty analysis carried out with a single chemical mechanism put the intra-mechanism range a factor of three higher at $0.50 \pm 0.12$. Similar differences between inter-mechanism and intra-mechanism ranges were found for hydroxyl radical depletion but were up to a factor of six wider for ozone formation from incremental additions of organic compounds. The cause of the discrepancies between the inter- and intra-mechanism ranges was found to be the large uncertainties that are present in the laboratory determinations of the rate coefficients and product channel branching ratios of some key chemical reactions involving organic peroxy radicals and hydroperoxides. Whilst these large uncertainties are present in the laboratory determinations, there will be irreducible uncertainties in the predictions from the earth system and other chemistry-transport models of methane and tropospheric ozone trends since pre-industrial times and hence their contributions to the radiative forcing of climate change. Further definitive laboratory studies of the reaction rates and product yields of the reactions of the simple organic peroxy radicals and hydroperoxides are required to resolve and reduce current uncertainties in earth system and chemistry-transport model predictions.

\footnotetext{
* Corresponding author.

E-mail address: r.derwent@btopenworld.com (R.G. Derwent).
} 


\section{Introduction}

Ozone $\left(\mathrm{O}_{3}\right)$ is an important atmospheric pollutant that causes impacts on human health and vegetation and is also an important radiatively active trace gas (Monks et al., 2015). Ozone plays an important role in driving the atmospheric chemistry of the troposphere (Levy, 1972). Tropospheric chemistry acts as a removal process for the oxides of nitrogen $\left(\mathrm{NO}_{\mathrm{x}}\right)$, carbon monoxide $(\mathrm{CO})$, methane $\left(\mathrm{CH}_{4}\right)$, sulphur dioxide $\left(\mathrm{SO}_{2}\right)$ and a myriad of organic compounds (Crutzen, 1974). Tropospheric chemistry also acts as an $\mathrm{O}_{3}$ source in the sunlit polluted boundary layer and throughout the lower atmosphere.

To quantify the radiative forcing by $\mathrm{O}_{3}$ and hence is contribution to climate change, it is necessary to quantify the seasonal and spatial distributions of $\mathrm{O}_{3}$ in both the pre-industrial and present-day periods. Because of the high chemical reactivity of $\mathrm{O}_{3}$, the historic tropospheric $\mathrm{O}_{3}$ concentrations cannot be recovered from ice cores in the same manner as carbon dioxide $\left(\mathrm{CO}_{2}\right)$ (Raynaud and Barnola, 1985), $\mathrm{CH}_{4}$ (Etheridge et al., 1992) and nitrous oxide $\left(\mathrm{N}_{2} \mathrm{O}\right)$ (Khalil and Rasmussen, 1988), for example. Quantification of both the pre-industrial and present-day $\mathrm{O}_{3}$ distributions is possible using earth system models (ESMs) but observations to compare with the model calculations and guide their improvement are available only for the present-day. Such comparisons increase our confidence in the model-derived present-day $\mathrm{O}_{3}$ distribution. But, since such comparisons are not possible for the pre-industrial atmosphere, we must rely on other approaches to examine the confidence that we can have in the model-derived pre-industrial $\mathrm{O}_{3}$ distribution. Providing such an approach is the goal of our paper.

The description of the chemistry of the pre-industrial atmosphere in global chemistry-transport models is necessarily highly uncertain because of the paucity and representativeness of observational data to feed into global models. Reliance must therefore be placed on chemistry, deposition and transport schemes as well as on global emission inventories to correctly describe the transition in the atmospheric composition of the troposphere from pre-industrial times through to the present-day. This transition has been particularly marked in some of the trace gases that control the distribution of tropospheric $\mathrm{O}_{3}$, such as $\mathrm{CH}_{4}$, $\mathrm{NO}_{\mathrm{x}}$ and many organic compounds. Wang and Jacob (1988) used a three-dimensional tropospheric chemistry model to investigate pre-industrial $\mathrm{O}_{3}$ levels and describe some of the uncertainties and potential difficulties. Of particular importance in their study was the level of pre-industrial $\mathrm{NO}_{\mathrm{x}}$ emissions. Many of these difficulties still remain after the intervening three decades (Archibald et al., 2020b).

Tropospheric $\mathrm{O}_{3}$ chemistry is highly complex and there are many areas of uncertainty in the global chemistry-transport models (CTMs) used for policy predictions and the support of policy development for global climate change. Revell et al. (2018) and Wild et al. (2020) have explored the uncertainties in the predictions of present-day tropospheric composition arising from uncertainties in emissions, deposition and vertical exchange. Additionally, Newsome and Evans (2017) have considered uncertainties arising from the representation of atmospheric chemistry in the present-day atmosphere. In contrast, because there is a paucity of studies addressing uncertainties in the pre-industrial atmosphere, attention is focussed here on the uncertainties in the atmospheric chemistry of $\mathrm{O}_{3}$ and $\mathrm{CH}_{4}$ in the pre-industrial troposphere and its representation in global models. Global models have been the main tools for understanding the climate system and for predicting future climate change (IPCC, 1990; 1996; 2001; 2013). More recently, global climate models have incorporated atmospheric chemistry and biogeochemical processes, evolving into earth system models (Young et al., 2018; Sellar et al., 2019; Yukimoto et al., 2019). Earth system models (ESMs) are now recognised as the main tools for the prediction of the time evolution of the climate system, together with that of the distributions of all relevant radiatively-active trace gases and aerosols from the pre-industrial times through to the end of the century (IPCC, 2013).

In this study, an intercomparison has been set up to examine in detail the representation of the atmospheric chemistry of pre-industrial $\mathrm{CH}_{4}$
Table 1

The earth system and other global models, their chemical mechanisms employed in this intercomparison, together with their supporting references.

\begin{tabular}{ll}
\hline Model or chemical mechanism & References \\
\hline BCC-GEOS-CHEMv1.0 & Wu et al. (2019, 2020) \\
& Mao et al., 2010, 2013 \\
& Parrella et al., 2012 \\
& Emmerson and Evans (2009)* \\
& Emmons et al. (2020)* \\
Gettelman et al. (2019) & Tilmes et al. (2019) \\
& Dunne et al. (2020) \\
GFDL-ESM4 & Horowitz et al., 2019* \\
& Kelley et al. (2020) \\
GISS-E2-1-H & Shindell et al., 2001* \\
MRI-ESM2-0 & Deushi and Shibata, 2011* \\
& Yukimoto et al. (2019) \\
UKESM-1-0-LL & Sellar et al. (2019) \\
& Archibald et al. (2020a)* \\
MCMv3.3.1 & Jenkin et al. (2015)* \\
STOCHEM-CRI & Utembe (2010) \\
& Jenkin et al. (2019) \\
& Khan et al. (2021)* www.cri.york.ac.uk \\
\hline
\end{tabular}

Notes: *, denotes the reference supporting the chemical mechanism.

Table 2

Pre-industrial background mixing ratios for key species employed in the constrained box model. The second column gives the simplified conditions for a single location for use in the test and evaluation phase. The third column gives the range of assumed background environmental conditions which were derived from STOCHEM-CRI simulations at ninety global locations.

\begin{tabular}{lll}
\hline Species & $\begin{array}{l}\text { Simplified test } \\
\text { conditions }\end{array}$ & $\begin{array}{l}\text { Pre-industrial mixing } \\
\text { ratio }\end{array}$ \\
\hline $\mathrm{CH}_{4}$ & $700 \mathrm{ppb}$ & $705-843 \mathrm{ppb}$ \\
$\mathrm{O}_{3}$ & $15 \mathrm{ppb}$ & $7.4-20.6 \mathrm{ppb}$ \\
$\mathrm{CO}$ & $52 \mathrm{ppb}$ & $47-117 \mathrm{ppb}$ \\
$\mathrm{H}_{2}$ & $499 \mathrm{ppb}$ & $499 \mathrm{ppb}$ \\
$\mathrm{NO}$ & $3 \mathrm{ppt}$ & $0.15-15.2 \mathrm{ppt}$ \\
$\mathrm{NO}_{2}$ & $16 \mathrm{ppt}$ & $3.3-122 \mathrm{ppt}$ \\
$\mathrm{HNO}_{3}$ & & $0.9-126 \mathrm{ppt}$ \\
$\mathrm{PAN}$ & & $0.7-80 \mathrm{ppt}$ \\
$\mathrm{MPAN}$ & & $0-3.8 \mathrm{ppt}$ \\
$\mathrm{H}_{2} \mathrm{O}_{2}$ & & $0.02-1.3 \mathrm{ppb}$ \\
$\mathrm{CH}_{3} \mathrm{OOH}$ & & $0.003-0.9 \mathrm{ppb}$ \\
$\mathrm{HCHO} \mathrm{CH}_{3} \mathrm{CHO}$ & & $0.02-1.46 \mathrm{ppb}$ \\
$\mathrm{C}_{2} \mathrm{H}_{6}$ & & $1.6-120 \mathrm{ppt}$ \\
$\mathrm{C}_{3} \mathrm{H}_{8}$ & & $88-691 \mathrm{ppt}$ \\
$\mathrm{nC}_{4} \mathrm{H}_{10}$ & & $6-332 \mathrm{ppt}$ \\
$\mathrm{C}_{2} \mathrm{H}_{4}$ & & $0.9-488 \mathrm{ppt}$ \\
$\mathrm{C}_{3} \mathrm{H}_{6}$ & & $0-1.9 \mathrm{ppb}$ \\
$\mathrm{C}_{2} \mathrm{H}_{5} \mathrm{CHO}$ & & $0-0.88 \mathrm{ppb}$ \\
$\mathrm{CH}_{3} \mathrm{COCH}$ & $0-1.5 \mathrm{ppt}$ \\
$\mathrm{CH}_{3} \mathrm{OH}$ & & $0.17-1.5 \mathrm{ppb}$ \\
$\mathrm{C}_{5} \mathrm{H}_{8}$ & & $142-844 \mathrm{ppt}$ \\
$\mathrm{Atmospheric} \mathrm{number} \mathrm{density,}_{\text {molecule cm }}^{-3}$ & $2.3603 .10^{19}$ & $0-7.6 \mathrm{ppb}$ \\
$\mathrm{Water} \mathrm{vapour} \mathrm{number} \mathrm{density,}_{\text {molecule cm }}^{-3}$ & & \\
$\mathrm{Temperature,} \mathrm{K}^{5.6907 .10^{17}}$ & $1.84-2.516 .10^{19}$ \\
\hline & & \\
& 295.7 & $1.277-6.395 .10^{17}$ \\
& & $277.7-303.8$ \\
\hline
\end{tabular}

and $\mathrm{O}_{3}$ in six of the ESMs that took part in the sixth phase of the Coupled Model Intercomparison Project (CMIP6) (Eyring et al., 2016). The question is what are the likely levels of uncertainty in earth system model predictions of pre-industrial $\mathrm{CH}_{4}$ and $\mathrm{O}_{3}$ chemistry. We show that inter-model (or inter-mechanism) range is a poor predictor of likely uncertainty which is driven by the uncertainties in a small number of key reaction rate coefficients and reaction product yields. 


\section{Methods}

\subsection{The constrained box model}

This intercomparison employed a constrained box-model approach that has previously been applied to the polluted boundary layer (Derwent, 2017) and to the background troposphere (Derwent, 2020). Here, the constrained box-model is focussed on the representation of the atmospheric chemistry of $\mathrm{O}_{3}$ and $\mathrm{CH}_{4}$ in the pre-industrial atmosphere and its representation in earth system and other global chemistry-transport models. The formulation of the constrained box-model was based on the Photochemical Trajectory Model (PTM), the details of which are given elsewhere (Derwent et al., 2010). In this application, wet and dry deposition, exchange with the free troposphere and emission processes have been switched off, leaving the complete focus on the chemical development of $\mathrm{O}_{3}$ and $\mathrm{CH}_{4}$ and that of the hydroxyl $(\mathrm{OH})$ radical species that drives it.

In a box model, a differential equation of the form:

$\mathrm{dc}_{\mathrm{i}} / \mathrm{dt}=\mathrm{P}_{\mathrm{i}}-\mathrm{l}_{\mathrm{i}} \mathrm{c}_{\mathrm{i}}$

was set up for each model species, $i$, where $c_{i}$ is the concentration of species, $i$, in the box, $P_{i}$ is its production rate from chemistry and $l_{i}$ is the first order loss coefficient arising from chemistry. In a constrained box model, the above differential equation is modified by the addition of a net flux, $F_{i}$, to the right-hand side of the equation so that the rate of change of the species, $i$, remains zero and its concentration remains constant at the constrained value, $\mathrm{c}_{\mathrm{i}}{ }^{*}$, listed in Table 2:

$\mathrm{dc}_{\mathrm{i}} / \mathrm{dt}=0=\mathrm{P}_{\mathrm{i}}-\mathrm{l}_{\mathrm{i}} \mathrm{c}_{\mathrm{i}}^{*}+\mathrm{F}_{\mathrm{i}}$

The Gear's method automatic numerical integrator FACSIMILE (Curtis and Sweetenham, 1987) returns the flux, $\mathrm{F}_{\mathrm{i}}$, required at the end of each time step to maintain the concentrations of each species at its constraint. This flux is then integrated over a time period of 5 days to give the time-integrated production or loss flux (depending on its sign) for that species. The output of the constrained box model is therefore the time-integrated production or loss fluxes for each of the upwards of twenty-two constrained species. Particular focus was given in this study to the time-integrated ozone production flux, $\mathrm{P}_{\mathrm{O} 3}$.

For the many species without constrained values, these species would reach some form of local instantaneous photochemical steady state and their diurnally-varying concentrations would be set by equations of the form of (1) above. Their concentrations were averaged over the 5-day time period and provided another set of outputs. Particular focus was given to the 5-day average hydroxyl radical number density, $(\underline{\mathrm{OH}})$, together with those of the hydroperoxyl $\left(\underline{\mathrm{HO}}_{2}\right)$ and the methylperoxy $\left(\underline{\mathrm{CH}}_{3} \underline{\mathrm{O}}_{2}\right)$.

\subsection{Chemical mechanisms employed in the intercomparison}

Table 1 summarises the details of the eight chemical mechanisms studied, together with their supporting literature references. They varied in complexity from the highly detailed and explicit Master Chemical Mechanism (MCM) v3.3.1 (https://mcm.york.ac.uk) to the condensed and parameterised mechanisms that are typically employed in earth system and other global models. The CESM2-WACCM and GFDL-ESM4 earth system models utilise chemical mechanisms which owe their origins to the MOZART family of mechanisms (Emmons et al., 2010; https://www2.acom.ucar.edu/gcm/mozart). UKESM1-0-LL and STOCHEM-CRI models employ mechanisms that are descended from the MCM, the BCC-GEOS-CHEMv1.0 from the GEOS-CHEM mechanism and the GISS-E2-1-H and the MRI-ESM2.0 from the Carbon Bond series of mechanisms (ENVIRON, 2005). Broadly speaking, rate coefficients for five mechanisms (BCC-GEOS-CHEMv1.0, CESM2-WACCM, GFDL-ESM4, GISS-E2-1-H and MRI-ESM2.0) are based on the JPL evaluated chemical kinetic data compilation (Burkholder et al., 2015) and for three mechanisms (STOCHEM-CRI, UKESM1-0-LL and MCMv3.3.1) on the IUPAC evaluation (Amman et al., 2013).

The mechanisms were, however, not implemented as published but were harmonised to minimise the influence of publication date. The first harmonisation addressed the so-called 'inorganic' chemistry. This set of close to fifty chemical reactions establishes the fast photochemical balance, involving the hydroxyl $(\mathrm{OH})$, hydroperoxy $\left(\mathrm{HO}_{2}\right)$ and oxygen $\left(\mathrm{O}^{1} \mathrm{D}\right.$ and $\mathrm{O}^{3} \mathrm{P}$ ) atoms and their reactions with nitric oxide (NO), nitrogen dioxide $\left(\mathrm{NO}_{2}\right)$, ozone $\left(\mathrm{O}_{3}\right)$, water vapour, carbon monoxide (CO), hydrogen $\left(\mathrm{H}_{2}\right)$ and sulphur dioxide $\left(\mathrm{SO}_{2}\right)$. The 'inorganic' chemistry provided with each mechanism was removed and replaced with a set of 49 chemical reaction pathways and rate coefficients, together with their temperature and pressure dependences, taken from IUPAC (http://i upac.pole-ether.fr/) (Amman et al., 2013). By harmonising the 'inorganic' chemistry, we are not saying that the uncertainties in this chemistry are unimportant but merely that our present focus is on the $\mathrm{C}_{1}-\mathrm{C}_{3}$ chemistry of $\mathrm{CH}_{4}$ and $\mathrm{O}_{3}$. Indeed, there have been several studies in the literature that point to the importance of 'inorganic chemistry as a source of uncertainty in chemistry-transport models (Newsome and Evans, 2017; Revell et al., 2018; Wild et al., 2019).

The second harmonisation involved the photolysis rate coefficients. All photolysis rate coefficients provided with each mechanism were replaced with a standard set taken from the MCM website (http://mcm. york.ac.uk/parameters/photolysis_parameters.htt) for present-day conditions. In particular, this harmonisation step applied to the photolysis rates for the aldehydes: formaldehyde ( $\mathrm{HCHO})$, acetaldehyde $\left(\mathrm{CH}_{3} \mathrm{CHO}\right)$ and propionaldehyde $\left(\mathrm{C}_{2} \mathrm{H}_{5} \mathrm{CHO}\right)$, for the ketone: acetone $\left(\mathrm{CH}_{3} \mathrm{COCH}_{3}\right)$ and for methyl hydroperoxide $\left(\mathrm{CH}_{3} \mathrm{OOH}\right)$ and the higher hydroperoxides $(\mathrm{ROOH})$. In addition, some chemical mechanisms treated the photolysis of methyl nitrate $\left(\mathrm{CH}_{3} \mathrm{NO}_{3}\right)$. By harmonising photolysis rate coefficients, we do not wish to convey the impression that photolysis rates are an unimportant source of model uncertainty but merely that our present focus is on the choice of thermal rate coefficients for the $\mathrm{C}_{1}-\mathrm{C}_{3}$ chemistry used in earth system and other chemistry-transport models. Indeed, Hall et al. (2018) described a detailed comparison of the photolysis rates from nine chemistry-transport models (including several of those models whose chemical mechanisms are studied here) with aircraft measurements and showed the importance of the uncertainties in cloud impacts on tropospheric chemistry.

The final harmonisation involved the rate coefficients for the formation and decomposition of the peroxyacyl nitrates. Again, these were replaced with a standard set of rate coefficients, together with their pressure and temperature dependences taken from the MCM website (http://mcm.york.ac.uk/parameters/complex.htt). The remainders of each mechanism, particularly the reactions of $\mathrm{CH}_{4}$, methylperoxy $\left(\mathrm{CH}_{3} \mathrm{O}_{2}\right)$, methyl hydroperoxide $\left(\mathrm{CH}_{3} \mathrm{OOH}\right)$, formaldehyde $(\mathrm{HCHO})$ and those of ethane, propane and acetone were implemented exactly as laid out in the published details of the earth system or global chemistrytransport model. The details of the $\mathrm{CH}_{4}$ chemistry and that of the other $\mathrm{C}_{1}$ compounds implemented for each of the eight mechanisms are provided in Table S1 of the Supplementary Information, for ethane and other $\mathrm{C}_{2}$ compounds in Table $\mathrm{S} 2$ and for propane and acetone in Table S3.

It is understood that these harmonisation steps may well move the mechanisms away from the conditions and chemical regimes under which they were developed by their originators. This was considered inevitable. As a result, the performance of the mechanisms may be different from that if no changes had been made. Due to the nature of the intercomparison, no treatments were included of halogen or heterogeneous chemistry with any of the chemical mechanisms.

\subsection{Background environmental conditions}

Any intercomparison of chemical mechanisms needs input data on background environmental conditions to set up an appropriate chemical regime to frame the evaluation. In this study, output has been taken from 
STOCHEM-CRI (Derwent et al., 2015) for pre-industrial conditions and was used to provide plausible meteorological and mixing ratios for a number of trace gases at ninety locations close to the surface spread for mid-July conditions. The chosen locations were in the tropics and temperate latitudes, sited on a $20^{\circ}$ latitude by $20^{\circ}$ longitude grid covering the latitude range from $37.5^{\circ} \mathrm{S}$ to $42.5^{\circ} \mathrm{N}$ and from $162.5^{\circ} \mathrm{E}$ to $177.5^{\circ} \mathrm{W}$. By choosing locations spread over both hemispheres, we have automatically accounted for summer and winter photochemical conditions. The trace gases, of which there are twenty-two in all, see Table 2, included ozone precursors and reaction products with atmospheric lifetimes of the order of minutes and longer. Free radical species have much shorter lifetimes and were not set up in the same way but were allowed to establish their own levels based on the time-dependent photochemical activity in each of the constrained box model calculations.

One of the chemical mechanisms employed in one of the earth system models (GISS-E2-1-H) operated with a $\mathrm{C}_{1}$-only chemistry and, in this respect, was quite distinct from the others. The other chemical mechanisms will have contributions to the number densities of $\mathrm{CH}_{3} \mathrm{O}_{2}$ from the oxidation of a range of $\mathrm{C}_{2}-\mathrm{C}_{3}$ organic compounds, in addition to those from $\mathrm{CH}_{4}$, methanol $\left(\mathrm{CH}_{3} \mathrm{OH}\right)$ and methyl hydroperoxide $\left(\mathrm{CH}_{3} \mathrm{OOH}\right)$. During the chemical mechanism testing and evaluation phase, this may influence the apparent performance of the mechanisms and may introduce bias into the intercomparison. Therefore, a much more simplified set of background environmental conditions was drawn up for the testing and evaluation phase. This simplified set of constraints addressed only $\mathrm{CH}_{4}, \mathrm{O}_{3}, \mathrm{H}_{2}, \mathrm{NO}$ and $\mathrm{NO}_{2}$ and the details are presented in the second column of Table 2 and considered only a single location.

In all other model experiments, the full set of 90 background locations were employed with the full range of trace gas composition data. The third column of Table 2 gives the range of variables calculated by STOCHEM-CRI at the ninety locations which are used to constrain the box model calculations.

\subsection{Description of the Monte Carlo uncertainty analysis}

There were three steps in our Monte Carlo assessment of uncertainties (Derwent et al., 2018) in the constrained box model predictions due to uncertainties in the input chemical kinetic data. In the first step, the constrained box model code was altered to accept a multiplier for each model chemical kinetic input parameter, scaling the evaluated 'best estimate' values. In the second step, the uncertain input ranges for each parameter were sampled quasi-randomly and input values were set for the initialisation of each constrained box model run. In the third step, the constrained box model was run repeatedly a large number, typically 1,000 , times with each run having a different random selection of chemical kinetic input parameters. Each constrained box model run returned the five-day time-integrated $\underline{\mathrm{OH}}, \underline{\mathrm{HO}_{2}}$ and $\underline{\mathrm{CH}}_{3} \underline{\mathrm{O}}_{2}$ and the time-integrated fluxes through each chemical reaction. Because all other constrained box model inputs remained exactly the same, differences in the model outputs could be accurately discerned.

For each chemical kinetic input parameter selected for uncertainty analysis, 5-95\% $(2-\sigma)$ confidence ranges were established based on multiplicative scaling about the 'best estimate' values. The upper and lower values for these ranges were taken from the chemical kinetic data evaluations (Burkholder et al., 2015; Amman et al., 2013). Probability distributions within these ranges were taken to be equally distributed on either side of the best estimates', that is to say 'top hat' in shape (Derwent et al., 2018). A 'top hat' distribution was chosen because it is simple and straightforward. We note that Newsome and Evans (2017) adopted a 'normal' distribution whereas Revell et al. (2018) and Wild et al. (2019) adopted a 'top hat' distribution as here.

\subsection{Testing and evaluating the constrained box model}

The constrained box model was set up with each of the eight
Table 3

Time-averaged photochemical ozone production rates $\left(\mathrm{P}_{\mathrm{O} 3}\right)$ and number densities of $\mathrm{OH}(\mathrm{OH})$ and $\mathrm{HO}_{2}\left(\mathrm{HO}_{2}\right)$ estimated with the constrained box model with each chemical mechanism under the simplified test conditions in the preindustrial atmosphere.

\begin{tabular}{llll}
\hline Mechanism & $\mathrm{P}_{\mathrm{O} 3}, \mathrm{ppb} \mathrm{hr}^{-1}$ & $\underline{\mathrm{OH}}, 10^{6} \mathrm{~cm}^{-3}$ & $\underline{\mathrm{HO}_{2}}, 10^{8} \mathrm{~cm}^{-3}$ \\
\hline BCC-GEOS-CHEMv1.0 & 0.0409 & 2.024 & 1.477 \\
CESM2-WACCM & 0.0410 & 2.023 & 1.474 \\
GFDL-ESM4 & 0.0409 & 2.024 & 1.477 \\
GISS-E2-1-H & 0.0422 & 1.915 & 1.402 \\
MRI-ESM2.0 & 0.0406 & 2.045 & 1.504 \\
UKESM1-0-LL & 0.0399 & 2.102 & 1.542 \\
STOCHEM-CRI & 0.0409 & 2.027 & 1.481 \\
MCMv3.3.1 & 0.0407 & 2.043 & 1.493 \\
Fractional range & 0.064 & 0.071 & 0.10 \\
\hline
\end{tabular}

Notes: The number of decimal places does not represent intrinsic accuracy but is merely to facilitate comparisons.

Fractional range $=($ maximum-minimum $)$ /average.

chemical mechanisms from the earth system and global models from Table 1 and the simplified set of background environmental conditions from the second column of Table 2 for a single location. For each chemical mechanism, the constrained box model was integrated for five days and the time-averaged net rate of $\mathrm{O}_{3}$ (production - loss) required to maintain its constrained mixing ratio was noted. The instantaneous $\mathrm{OH}$ and $\mathrm{HO}_{2}$ number densities averaged over the five-day period were also calculated and these three numbers for the eight chemical mechanisms are presented in Table 3.

Under the simplified background environmental conditions, the atmospheric chemistry was driven by the photolysis of $\mathrm{O}_{3}$ to give excited oxygen atoms, which reacted with water vapour to produce $\mathrm{OH}$ :

$\mathrm{O}_{3}+\mathrm{h} \nu \rightarrow \mathrm{O}_{2}+\mathrm{O}^{1} \mathrm{D}$

$\mathrm{O}\left({ }^{1} \mathrm{D}\right)+\mathrm{H}_{2} \mathrm{O} \rightarrow \mathrm{OH}+\mathrm{OH}$

$\mathrm{OH}$ reacted predominantly with carbon monoxide (CO) to generate $\mathrm{HO}_{2}$ :

$\mathrm{OH}+\mathrm{CO} \rightarrow \mathrm{H}+\mathrm{CO}_{2}$

$\mathrm{H}+\mathrm{O}_{2}+\mathrm{M} \rightarrow \mathrm{HO}_{2}+\mathrm{M}$

$\mathrm{HO}_{2}$ has a number of possible fates, including the regeneration of $\mathrm{OH}$ by:

$\mathrm{HO}_{2}+\mathrm{NO} \rightarrow \mathrm{OH}+\mathrm{NO}_{2}$

$\mathrm{HO}_{2}+\mathrm{O}_{3} \rightarrow \mathrm{OH}+\mathrm{O}_{2}+\mathrm{O}_{2}$

However, not all of the $\mathrm{HO}_{2}$ reacted with $\mathrm{NO}$ or $\mathrm{O}_{3}$, as some recombined to form hydrogen peroxide $\left(\mathrm{H}_{2} \mathrm{O}_{2}\right)$ :

$\mathrm{HO}_{2}+\mathrm{HO}_{2}+\mathrm{M} \rightarrow \mathrm{H}_{2} \mathrm{O}_{2}+\mathrm{O}_{2}+\mathrm{M}$

The $\mathrm{HO}_{2}$ that recombined in this way, acted as a sink for free radicals. Consequently, about one quarter of the $\mathrm{OH}+\mathrm{CO}$ reaction flux was recycled back to $\mathrm{OH}$ and three quarters acted as a sink for $\mathrm{OH}$ under the simplified background environmental conditions.

$\mathrm{OH}$ reacted with a wide range of trace gases in addition to $\mathrm{CO}$. The reactions of $\mathrm{OH}$ with $\mathrm{H}_{2}$ and $\mathrm{O}_{3}$ acted in a similar manner as the $\mathrm{OH}+$ $\mathrm{CO}$ reaction by recycling a fraction of the $\mathrm{OH}$ through to $\mathrm{HO}_{2}$. The reactions of $\mathrm{OH}$ with $\mathrm{HO}_{2}$ and $\mathrm{NO}_{2}$, however, acted as total sinks for $\mathrm{OH}$ since their reaction products did not recycle back to $\mathrm{OH}$ by way of $\mathrm{HO}_{2}$ :

$\mathrm{OH}+\mathrm{HO}_{2} \rightarrow \mathrm{H}_{2} \mathrm{O}+\mathrm{O}_{2}$

$\mathrm{OH}+\mathrm{NO}_{2}+\mathrm{M} \rightarrow \mathrm{HNO}_{3}+\mathrm{M}$

All of the reactions of $\mathrm{OH}, \mathrm{HO}_{2}, \mathrm{H}_{2} \mathrm{O}_{2}, \mathrm{CO}, \mathrm{H}_{2}$ and $\mathrm{NO}_{\mathrm{x}}$ were included 
in the 'inorganic' reactions of the fast photochemical balance of the troposphere and their rate coefficients were standardised and harmonised to be identical within each of the eight chemical mechanisms studied.

The chemical mechanisms diverged in their treatment of the atmospheric chemistry of $\mathrm{CH}_{4}$ and its $\mathrm{C}_{1}$ reaction products following the reaction of $\mathrm{OH}$ with $\mathrm{CH}_{4}$ :

$\mathrm{OH}+\mathrm{CH}_{4} \rightarrow \mathrm{CH}_{3}+\mathrm{H}_{2} \mathrm{O}$

Methyl $\left(\mathrm{CH}_{3}\right)$ radicals rapidly reacted with molecular oxygen to produce $\mathrm{CH}_{3} \mathrm{O}_{2}$ (Calvert et al., 2008):

$\mathrm{CH}_{3}+\mathrm{O}_{2}+\mathrm{M} \rightarrow \mathrm{CH}_{3} \mathrm{O}_{2}+\mathrm{M}$

$\mathrm{CH}_{3} \mathrm{O}_{2}$ had a number of fates under tropospheric conditions:

$\mathrm{CH}_{3} \mathrm{O}_{2}+\mathrm{NO} \rightarrow \mathrm{CH}_{3} \mathrm{O}+\mathrm{NO}_{2}$

$\mathrm{CH}_{3} \mathrm{O}_{2}+\mathrm{HO}_{2} \rightarrow$ products

$\mathrm{CH}_{3} \mathrm{O}_{2}+\mathrm{CH}_{3} \mathrm{O}_{2} \rightarrow$ products

The reaction of $\mathrm{CH}_{3} \mathrm{O}_{2}$ with NO produced methoxy $\left(\mathrm{CH}_{3} \mathrm{O}\right)$ whose main fate was to react with oxygen to produce $\mathrm{HO}_{2}$ and $\mathrm{HCHO}$ :

$\mathrm{CH}_{3} \mathrm{O}+\mathrm{O}_{2} \rightarrow \mathrm{HO}_{2}+\mathrm{HCHO}$

This reaction produced $\mathrm{HO}_{2}$ which could then go on to react with NO or $\mathrm{O}_{3}$ to regenerate the $\mathrm{OH}$. In consequence, about one twentieth of the reaction flux through $\mathrm{OH}+\mathrm{CH}_{4}$ was recycled back to $\mathrm{OH}$ and the remainder acted as a sink for $\mathrm{OH}$ under the simplified background environmental conditions.

None of the rate coefficients defining the atmospheric chemistry of $\mathrm{CH}_{4}$ and its $\mathrm{C}_{1}$ reaction products were standardised or harmonised between the eight different chemical mechanisms, except for the photolysis reactions of $\mathrm{HCHO}$ and $\mathrm{CH}_{3} \mathrm{OOH}$. The chemical mechanism developers provided their own unique descriptions of the chemical processes involved, including rate coefficients and reactions products for the $\mathrm{CH}_{3} \mathrm{O}_{2}+\mathrm{HO}_{2}$ and $\mathrm{CH}_{3} \mathrm{O}_{2}+\mathrm{CH}_{3} \mathrm{O}_{2}$ reactions. Any divergences in the base case model results for $\mathrm{P}_{\mathrm{O}}, \mathrm{OH}, \mathrm{HO}_{2}$ and $\mathrm{CH}_{3} \mathrm{O}_{2}$ necessarily stemmed wholly from any divergences in the representation of the atmospheric chemistry of $\mathrm{CH}_{4}$ and its $\mathrm{C}_{1}$ chemistry among the eight chemical mechanisms.

Overall, the results presented in Table 3 show a reasonable level of agreement, that is to say within $\pm 5 \%$, across the three metrics and eight chemical mechanisms despite many apparent divergences in the representation of the $\mathrm{CH}_{4}$ and $\mathrm{C}_{1}$ chemistry illuminated in Table $\mathrm{S} 1$. The intermechanism ranges for the $\mathrm{P}_{\mathrm{O}}, \underline{\mathrm{OH}}$ and $\underline{\mathrm{HO}}_{2}$ metrics expressed as a fraction of the inter-mechanism average were $0.064,0.071$ and 0.10 as shown in Table 3. From this level of agreement for the three metrics, it was concluded that the harmonisation and standardisation measures, together with the simplified background environmental conditions had ensured that all the chemical mechanisms have been implemented reasonably accurately within the constrained box model without the introduction of distortion or bias and with a reasonable level of conformity.

Having said that, there are small differences between the results for the different metrics and between the different chemical mechanisms, see Table 3, and it is important to offer some explanation for these differences. Across the three metrics, there was a tendency for the GISS-E21-H and UKESM1-0-LL mechanisms to generate results that lay towards the limits of the inter-mechanism ranges and hence the investigation of the divergences between the chemical mechanisms in Table 3 began with them.

Examination of the representation of $\mathrm{C}_{1}$ chemistry in Table $\mathrm{S} 1$ of the Supplementary Information indicated four minor differences between its implementation in GISS-E2-1-H and in the other earth system models. These involved the $\mathrm{NO}_{3}+\mathrm{HCHO}, \mathrm{OH}+\mathrm{CH}_{3} \mathrm{OOH}, \mathrm{CH}_{3} \mathrm{O}_{2}+\mathrm{CH}_{3} \mathrm{O}_{2}$ and
$\mathrm{OH}+\mathrm{CH}_{4}$ reaction rate coefficients. A series of one-at-a-time (OAT) sensitivity experiments was performed where each of the above rate coefficients were replaced with those from another earth system model (usually CESM2-WACCM). Three sensitivity experiments revealed trivial impacts from rate coefficient substitution but the sensitivity experiment involving the rate coefficient and product yields for $\mathrm{OH}+\mathrm{CH}_{3} \mathrm{OOH}$ was found to account for all of the underestimation of $\underline{\mathrm{OH}}$ and $\underline{\mathrm{HO}}_{2}$ and the overestimation of $\mathrm{P}_{\mathrm{O} 3}$ found with GISS-E2-1-H, see Table 3 , when compared to the average of all model chemical mechanisms.

In an analogous manner, twelve differences were found in Table S1 of the Supplementary Information between the implementation of the $\mathrm{C}_{1}$ chemistry in the UKESM1-0-LL model compared with that in some of the other earth system models. OAT sensitivity tests revealed two differences that accounted for the whole of the apparent overestimation of $\mathrm{OH}$ and $\mathrm{HO}_{2}$ and the underestimation of $\mathrm{P}_{\mathrm{O} 3}$ shown in Table 3, relative to other model mechanisms. As with the GISS-E2-1-H model mechanism, these differences in UKESM1-0-LL both involved the $\mathrm{OH}+\mathrm{CH}_{3} \mathrm{OOH}$ reaction, through the choice of rate coefficient and the specification of the relative yields for the two reactive channels for this reaction.

It is also instructive to compare the predictions in Table 3 from the MCMv3.3.1 and STOCHEM-CRI since, although the results were very similar, they were not identical as expected. The $\mathrm{P}_{\mathrm{O}}, \underline{\mathrm{OH}}$ and $\underline{\mathrm{HO}_{2}}$ differed by $+0.47 \%,-0.77 \%$ and $-0.78 \%$, respectively. Detailed inspection of the chemical kinetic data employed in each chemical mechanism revealed two sets of differences, despite the application of the harmonisation and standardisation procedures. The first difference involved the inclusion in MCMv3.3.1 but not in STOCHEM-CRI of the formation and thermal decomposition of methyl peroxy nitrate $\left(\mathrm{CH}_{3} \mathrm{O}_{2} \mathrm{NO}_{2}\right)$. The second difference was the number of routes included for the $\mathrm{CH}_{3} \mathrm{O}_{2}+\mathrm{HO}_{2}$ reaction: two, as in MCMv3.3.1, or one, as in STOCHEM-CRI. OAT sensitivity tests revealed that the formation and decomposition of $\mathrm{CH}_{3} \mathrm{O}_{2} \mathrm{NO}_{2}$ was entirely unimportant in terms of the four metrics in Table 3 under the simplified background environmental conditions as expected based on Khan et al. (2020) but that the implementation of the second minor route in $\mathrm{CH}_{3} \mathrm{O}_{2}+\mathrm{HO}_{2}$ forming $\mathrm{HCHO}$ accounted for all the differences between MCMv3.3.1 and STOCHEM-CRI.

In summary, all the differences in $\mathrm{P}_{3}, \underline{\mathrm{OH}}$ and $\underline{\mathrm{HO}}_{2}$ apparent in Table 3 can be accounted for by differences in the implementation of the two reactions: $\mathrm{OH}+\mathrm{CH}_{3} \mathrm{OOH}$ and $\mathrm{CH}_{3} \mathrm{O}_{2}+\mathrm{HO}_{2}$ across the eight chemical mechanisms. Considering first the $\mathrm{OH}+\mathrm{CH}_{3} \mathrm{OOH}$ reaction, then it is noted that the two major compilations of chemical kinetic data for atmospheric modelling purposes: IUPAC (Amman et al., 2013) and JPL (Burkholder et al., 2015), diverge significantly in their evaluations and recommendations for this reaction. Under the simplified environmental conditions, (see Table 2), the rate coefficients for the $\mathrm{OH}+$ $\mathrm{CH}_{3} \mathrm{OOH}$ reaction differ significantly: $1.00 \times 10^{-11} \mathrm{~cm}^{3}$ molecule ${ }^{-1} \mathrm{~s}^{-1}$ in IUPAC and $7.47 \times 10^{-12} \mathrm{~cm}^{3}$ molecule $\mathrm{e}^{-1} \mathrm{~s}^{-1}$ in JPL. However, both evaluations quote wide uncertainty limits for this reaction, such that the differences between the evaluations are not significant. IUPAC and JPL quote uncertainty ranges of $(0.5-2.0) \times 10^{-11} \mathrm{~cm}^{3}$ molecule ${ }^{-1} \mathrm{~s}^{-1}$ and $(0.38-1.45) \times 10^{-11} \mathrm{~cm}^{3}$ molecule ${ }^{-1} \mathrm{~s}^{-1}$, respectively. Furthermore, there are significant differences in the evaluations and recommendations for the branching ratios for the two routes for this reaction:

$\mathrm{OH}+\mathrm{CH}_{3} \mathrm{OOH} \rightarrow \mathrm{HCHO}+\mathrm{OH}+\mathrm{H}_{2} \mathrm{O}$ (minor channel) and.

$\mathrm{OH}+\mathrm{CH}_{3} \mathrm{OOH} \rightarrow \mathrm{CH}_{3} \mathrm{O}_{2}+\mathrm{H}_{2} \mathrm{O}$, (major channel).

These differences in evaluated and recommended chemical kinetic data have directly caused the discrepancies noted In Table 3, however, there is no clear basis by which to choose between the recommendations from the IUPAC and JPL data compilations for the $\mathrm{OH}+\mathrm{CH}_{3} \mathrm{OOH}$ reaction.

Considering the $\mathrm{CH}_{3} \mathrm{O}_{2}+\mathrm{HO}_{2}$ reaction, it is noted that the IUPAC (Amman et al., 2013) and the JPL (Burkholder et al., 2015) chemical data evaluations agree closely in their recommendations. However, both evaluations point to wide uncertainty ranges under the conditions of the simplified environmental conditions: (3.08-8.79) $\quad$ x $\quad 10^{-12} \mathrm{~cm}^{3}$ 


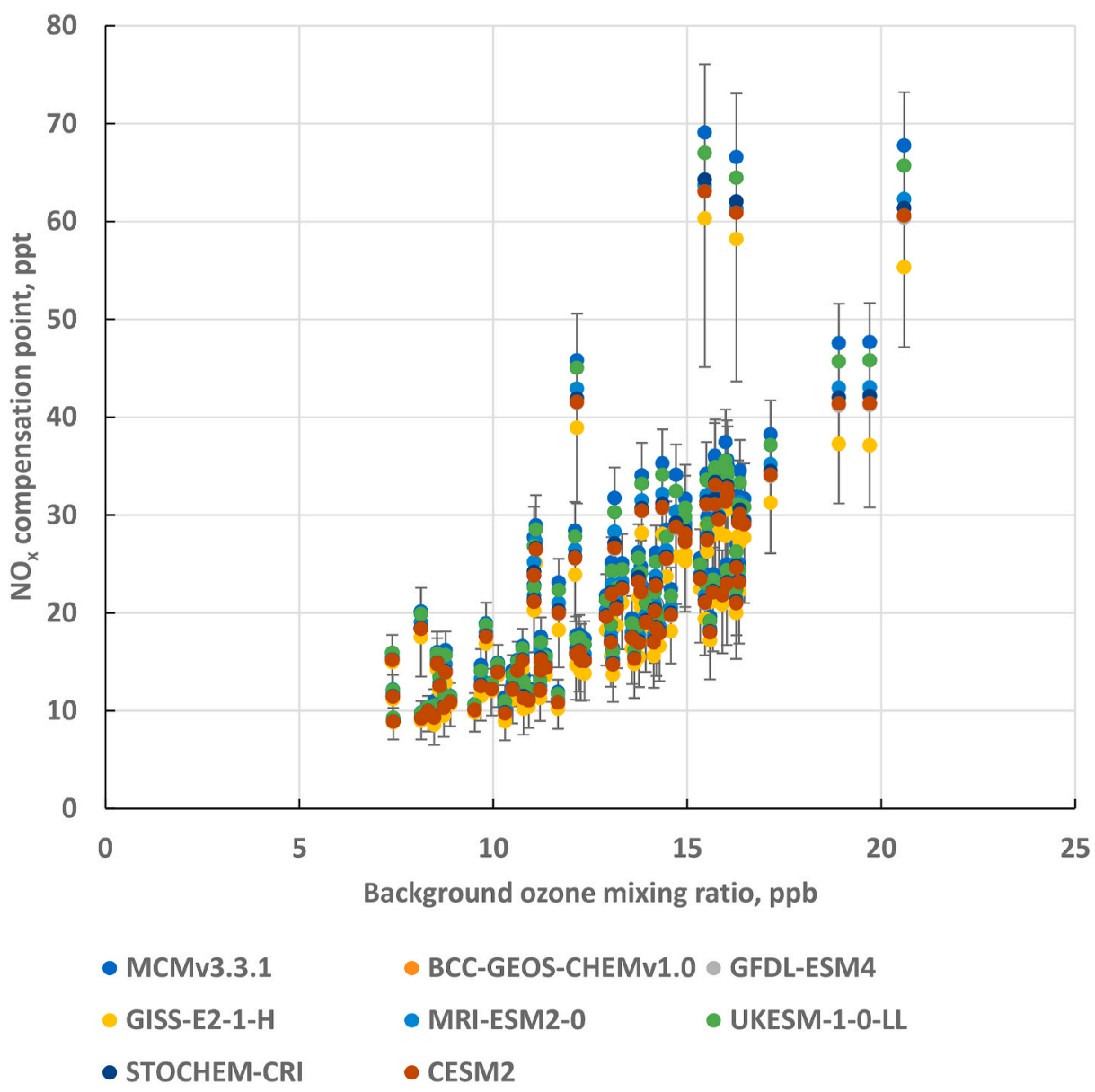

Fig. 1. Scatter plot of the $\mathrm{NO}_{\mathrm{x}}$ compensation points determined at each background location versus the background ozone mixing ratio for each model chemical mechanism. The error bars shown are for CESM2-WACCM based on the maximum and minimum values found in the Monte Carlo uncertainty analysis.

molecule ${ }^{-1} \mathrm{~s}^{-1}$ in JPL and (3.28-8.2) x $10^{-12} \mathrm{~cm}^{3}$ molecule $\mathrm{e}^{-1} \mathrm{~s}^{-1}$ in IUPAC. They disagree about the importance of the minor reaction channel. The recommended yield for the minor channel:

$\mathrm{CH}_{3} \mathrm{O}_{2}+\mathrm{HO}_{2} \rightarrow \mathrm{O}_{2}+\mathrm{HCHO}+\mathrm{H}_{2} \mathrm{O}$, versus the major channel:

$\mathrm{CH}_{3} \mathrm{O}_{2}+\mathrm{HO}_{2} \rightarrow \mathrm{O}_{2}+\mathrm{CH}_{3} \mathrm{OOH}$

is zero in JPL but is 0.1 in IUPAC. However, uncertainties are large and there is not a lot of difference between the evaluations. Removing the minor channel from the MCMv3.3.1 and STOCHEM-CRI, in agreement with the other mechanisms in Table S1, accounted for all the differences seen in the three metrics in Table 3 between the MCMv3.3.1 and STOCHEM-CRI.

\section{Application of the constrained box model to the impacts of $\mathrm{NO}_{\mathrm{x}}$ in the pre-industrial atmosphere}

The constrained box model was set up with a 'base case', using the pre-industrial background environmental conditions for $\mathrm{CH}_{4}, \mathrm{O}_{3}, \mathrm{CO}$ and $\mathrm{H}_{2}$ from a STOCHEM-CRI simulation (Derwent et al., 2015) for each of the 90 gridded locations and for each chemical mechanism taken from the third column of Table 2. The constrained mixing ratios for NO and $\mathrm{NO}_{2}$ were then reduced in $10 \%$ steps from their base case values and the $\mathrm{P}_{\mathrm{O} 3}, \underline{\mathrm{OH}}, \underline{\mathrm{HO}_{2}}$ and $\underline{\mathrm{CH}}_{3} \underline{\mathrm{O}}_{2}$ were noted. In addition, the time-integrated fluxes through each of the $\mathrm{C}_{1}$ reactions in Table $\mathrm{S} 1$ were monitored as the $\mathrm{NO}_{\mathrm{x}}$ mixing ratios were reduced. It was found that the time-integrated fluxes through the $\mathrm{O}_{3}$ source reactions:

$\mathrm{HO}_{2}+\mathrm{NO} \rightarrow \mathrm{OH}+\mathrm{NO}_{2}$, and.

$\mathrm{CH}_{3} \mathrm{O}_{2}+\mathrm{NO} \rightarrow \mathrm{CH}_{3} \mathrm{O}+\mathrm{NO}_{2}$, followed by
$\mathrm{CH}_{3} \mathrm{O}+\mathrm{O}_{2} \rightarrow \mathrm{HO}_{2}+\mathrm{HCHO}$

decreased step-wise in line with the $\mathrm{NO}_{\mathrm{x}}$ mixing ratios and that those through the $\mathrm{O}_{3}$ sink reactions:

$\mathrm{HO}_{2}+\mathrm{O}_{3} \rightarrow \mathrm{OH}+\mathrm{O}_{2}+\mathrm{O}_{2}$, and

$\mathrm{OH}+\mathrm{O}_{3} \rightarrow \mathrm{HO}_{2}+\mathrm{O}_{2}$

also did likewise. The decrease in the reaction flux through the $\mathrm{O}_{3}$ sink reactions thus acted as an apparent increase in the net $\mathrm{O}_{3}$ source. However, with all the chemical mechanisms, the decrease in the fluxes through $\mathrm{O}_{3}$ sinks was not enough to compensate for the decrease in the fluxes through $\mathrm{O}_{3}$ sources and so the net rate of $\mathrm{O}_{3}$ production decreased in step with the decrease in the $\mathrm{NO}_{\mathrm{x}}$ mixing ratios. At some point with the decreasing $\mathrm{NO}_{\mathrm{x}}$ mixing ratios, the net rate of $\mathrm{O}_{3}$ production changed sign from net production to net loss. This point is the $\mathrm{NO}_{\mathrm{x}}$ compensation point.

The $\mathrm{NO}_{\mathrm{x}}$ compensation points found at each of the 90 background troposphere locations varied from just below $10 \mathrm{ppt}$ to just below $70 \mathrm{ppt}$, with an average of $24 \pm 12 \mathrm{ppt}$ with MCMv3.3.1. The spatial patterns of the variations in compensation points across the 90 locations were closely similar between the different chemical mechanisms and were driven largely by the spatial pattern in the $\mathrm{O}_{3}$ mixing ratios in the background environmental conditions. As the background $\mathrm{O}_{3}$ mixing ratio increased from $7.4 \mathrm{ppb}$ to $20.6 \mathrm{ppb}$, the $\mathrm{NO}_{\mathrm{x}}$ compensation point increased from $9.3 \mathrm{ppt}$ to $68 \mathrm{ppt}$ with MCMv3.3.1. Scatter plots of the compensation points found with MCMv3.3.1 versus the other seven mechanisms were closely linear $\left(\mathrm{R}^{2}>0.97\right)$ and are presented in Fig. S1 


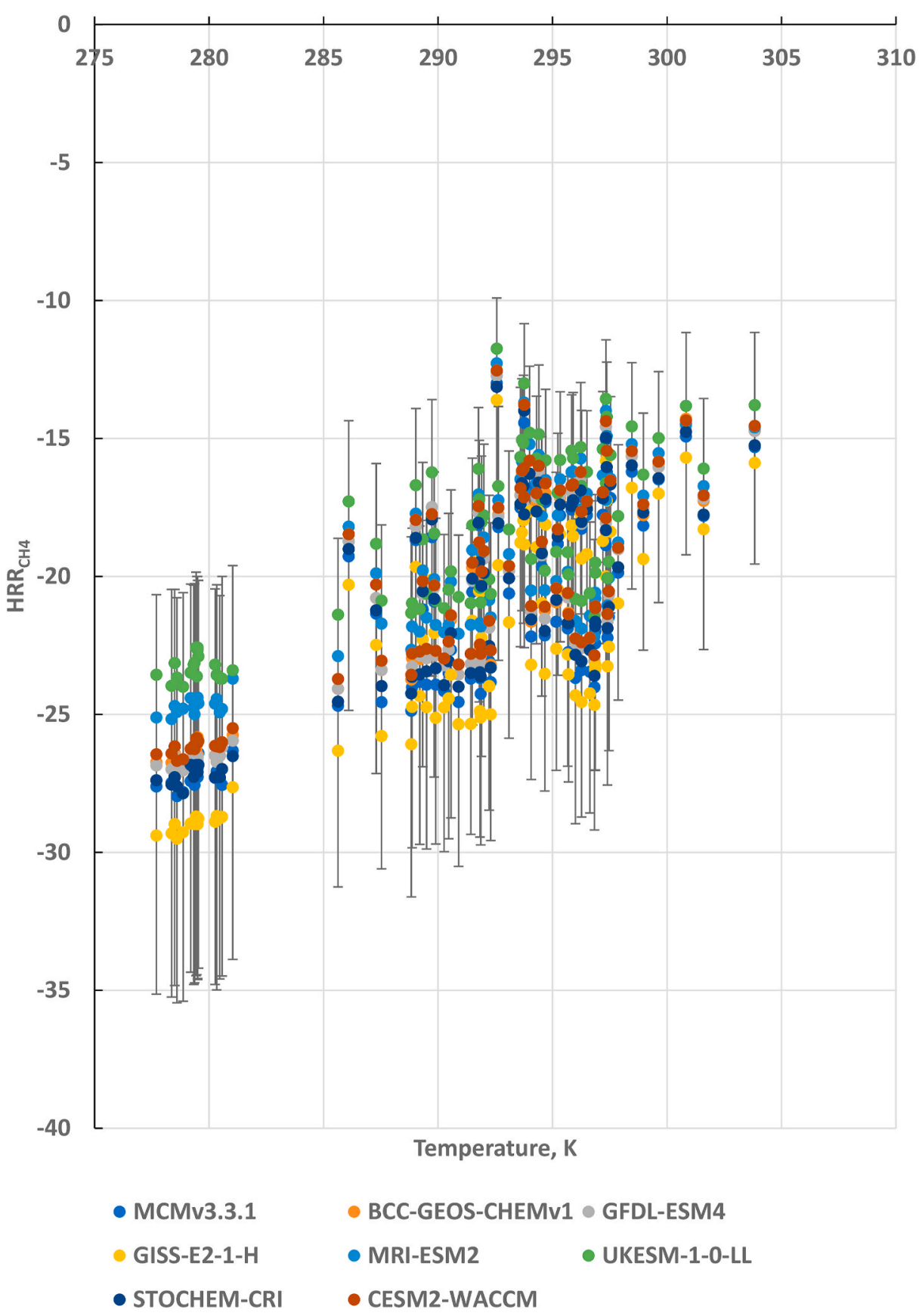

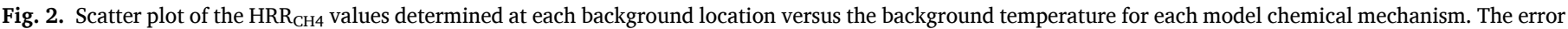
bars shown are for CESM2-WACCM based on the maximum and minimum values found in the Monte Carlo uncertainty analysis.

in the Supplementary Information. The slopes of the regression plots varied from 0.80 with GISS-E2-1-H to 0.96 with UKESM1-0-LL showing that the compensation points determined with the MCMv3.3.1 overestimated those from the other mechanisms by between 4 and $20 \%$ on average. An inter-mechanism uncertainty range was estimated at each of the 90 background locations, based on the maximum and minimum values over the eight chemical mechanisms. On this basis, the intermechanism range was about $0.17 \pm 0.12$ when expressed as a fraction of the average.

Closer inspection of the regression slopes versus MCMv3.3.1 in Fig. S1, showed that five mechanisms: BCC-GEOS-CHEMv1.0; CESM2WACCM; GFDL-ESM4; MRI-ESM2-0 and STOCHEM-CRI, gave values of slopes in a narrow range from 0.89 to 0.91 . The slope value for GISS-E2$1-\mathrm{H}$ at 0.80 was well outside of this range. OAT sensitivity experiments were performed to understand the possible influence of the four minor differences in the representation of $\mathrm{C}_{1}$ chemistry in GISS-E2-1-H as revealed in Table S1. Replacing the rate coefficient for the $\mathrm{OH}+\mathrm{MEPX}$ reaction with that from other earth system models, moved the slope versus MCMv3.3.1 from 0.80 to 0.89 , that is well within the range of the other models.

In an analogous manner, the slope versus MCMv3.3.1 for UKESM1-0LL in Fig. 1, with a value of 0.964 , was significantly higher than that for some other mechanisms. OAT sensitivity analyses were performed to understand the importance of the twelve differences found in Table S1 between the $\mathrm{C}_{1}$ chemistry in UKESM1-0-LL, compared with that in some other earth system models. Removing all these differences caused the slope versus MCMv3.3.1 in Fig. S1 to move from 0.964 to 0.895 , well within the range of the other earth system models. Of the many 
Table 4

Summary of the HRRs and OFPs estimated for each organic compound with each chemical mechanism, together with the estimated fractional inter-mechanism and with the intra-mechanism ranges from Monte Carlo uncertainty analyses.

\begin{tabular}{|l|l|l|l|l|}
\hline Mechanism & methane & ethane & acetone & propane \\
\hline
\end{tabular}

$\mathrm{HRR}=$ Response in $\underline{\mathrm{OH}}$ expressed as a ratio of the increment in the rate of organic compound oxidation in $10^{6} \mathrm{ppb} \mathrm{hr^{-1 }}$

\begin{tabular}{|l|c|c|c|c|}
\hline BCC-GEOS-CHEMv1.0 & $-20.8 \pm 8$ & $-21.1 \pm 7$ & $-10.8 \pm 6$ & $-18.7 \pm 6$ \\
\hline CESM2-WACCM & $-20.9 \pm 8$ & $-20.4 \pm 7$ & $-9.8 \pm 5$ & $-22.5 \pm 8$ \\
\hline GFDL-ESM4 & $-20.9 \pm 8$ & $-20.6 \pm 7$ & $-10.1 \pm 5$ & $-22.6 \pm 9$ \\
\hline GISS-E2-1-H & $-22.7 \pm 8$ & & & \\
\hline MRI-ESM2.0 & $-19.9 \pm 7$ & $-24.6 \pm 9$ & $-15.1 \pm 6$ & $-23.3 \pm 9$ \\
\hline UKESM1-0-LL & $-18.9 \pm 6$ & $-24.9 \pm 10$ & $-16.7 \pm 9$ & $-18.3 \pm 6$ \\
\hline & $-21.2 \pm 8$ & $-20.0 \pm 7$ & $-10.6 \pm 7$ & $-15.8 \pm 5$ \\
\hline STOCHEM-CRI & $-21.5 \pm 8$ & $-21.6 \pm 8$ & $-10.3 \pm 6$ & $-17.7 \pm 5$ \\
\hline MCMv3.3.1 & $0.18 \pm 0.05$ & $0.24 \pm 0.05$ & $0.63 \pm 0.2$ & $0.38 \pm 0.16$ \\
\hline $\begin{array}{l}\text { Fractional Inter- } \\
\text { mechanism range }\end{array}$ & $0.53 \pm 0.06$ & $0.45 \pm 0.09$ & $1.65 \pm 0.4$ & $0.69 \pm 0.07$ \\
\hline $\begin{array}{l}\text { Fractional Intra- } \\
\text { mechanism range }\end{array}$ & & & & \\
\hline
\end{tabular}

OFP $=$ Response in time-averaged rate of net ozone production expressed as a ratio of the increment in the rate of organic compound oxidation in $\mathrm{ppb} \mathrm{hr} \mathrm{hr}^{-1}$

\begin{tabular}{|l|l|l|l|l|}
\hline BCC-GEOS-CHEMv1.0 & $0.43 \pm 0.2$ & $0.64 \pm 0.5$ & $0.81 \pm 0.8$ & $0.50 \pm 0.3$ \\
\hline CESM2-WACCM & $0.43 \pm 0.2$ & $0.62 \pm 0.6$ & $0.81 \pm 0.9$ & $0.43 \pm 0.2$ \\
\hline GFDL-ESM4 & $0.43 \pm 0.2$ & $0.61 \pm 0.6$ & $0.57 \pm 0.7$ & $0.43 \pm 0.2$ \\
\hline GISS-E2-1-H & $0.48 \pm 0.2$ & & & \\
\hline MRI-ESM2.0 & $0.38 \pm 0.2$ & $0.64 \pm 0.6$ & $0.57 \pm 0.7$ & $0.44 \pm 0.2$ \\
\hline UKESM1-0-LL & $0.35 \pm 0.2$ & $0.69 \pm 0.3$ & $0.58 \pm 0.7$ & $0.40 \pm 0.3$ \\
\hline & $0.42 \pm 0.2$ & $0.70 \pm 0.6$ & $0.74 \pm 0.7$ & $0.39 \pm 0.3$ \\
\hline STOCHEM-CRI & $0.37 \pm 0.2$ & $0.70 \pm 0.6$ & $0.82 \pm 0.8$ & $0.33 \pm 0.2$ \\
\hline MCMv3.3.1 & $0.31 \pm 0.1$ & $0.18 \pm 0.08$ & $0.49 \pm 0.3$ & $0.43 \pm 0.2$ \\
\hline $\begin{array}{l}\text { Fractional Inter- } \\
\text { mechanism range }\end{array}$ & $0.42 \pm 0.03$ & $1.21 \pm 0.6$ & $0.91 \pm 0.8$ & $1.28 \pm 0.8$ \\
\hline $\begin{array}{l}\text { Fractional Intra- } \\
\text { mechanism range }\end{array}$ & & & & \\
\hline
\end{tabular}

differences removed, as in section 2.4 above, the most important differences were with the representation of the $\mathrm{OH}+\mathrm{CH}_{3} \mathrm{OOH}$ reaction and its two reaction pathways.

On this basis, we have been able to show how differences in the two major compilations of evaluated chemical kinetic data: JPL (Burkholder et al., 2015) and IUPAC (Ammann et al., 2013), for the $\mathrm{OH}+\mathrm{CH}_{3} \mathrm{OOH}$ and $\mathrm{CH}_{3} \mathrm{O}_{2}+\mathrm{HO}_{2}$ reactions have led to discernible differences appearing in the $\mathrm{NO}_{\mathrm{x}}$ compensation points estimated with the different chemical mechanisms in the pre-industrial atmosphere.

To construct an estimate of the likely uncertainty in the $\mathrm{NO}_{\mathrm{x}}$ 


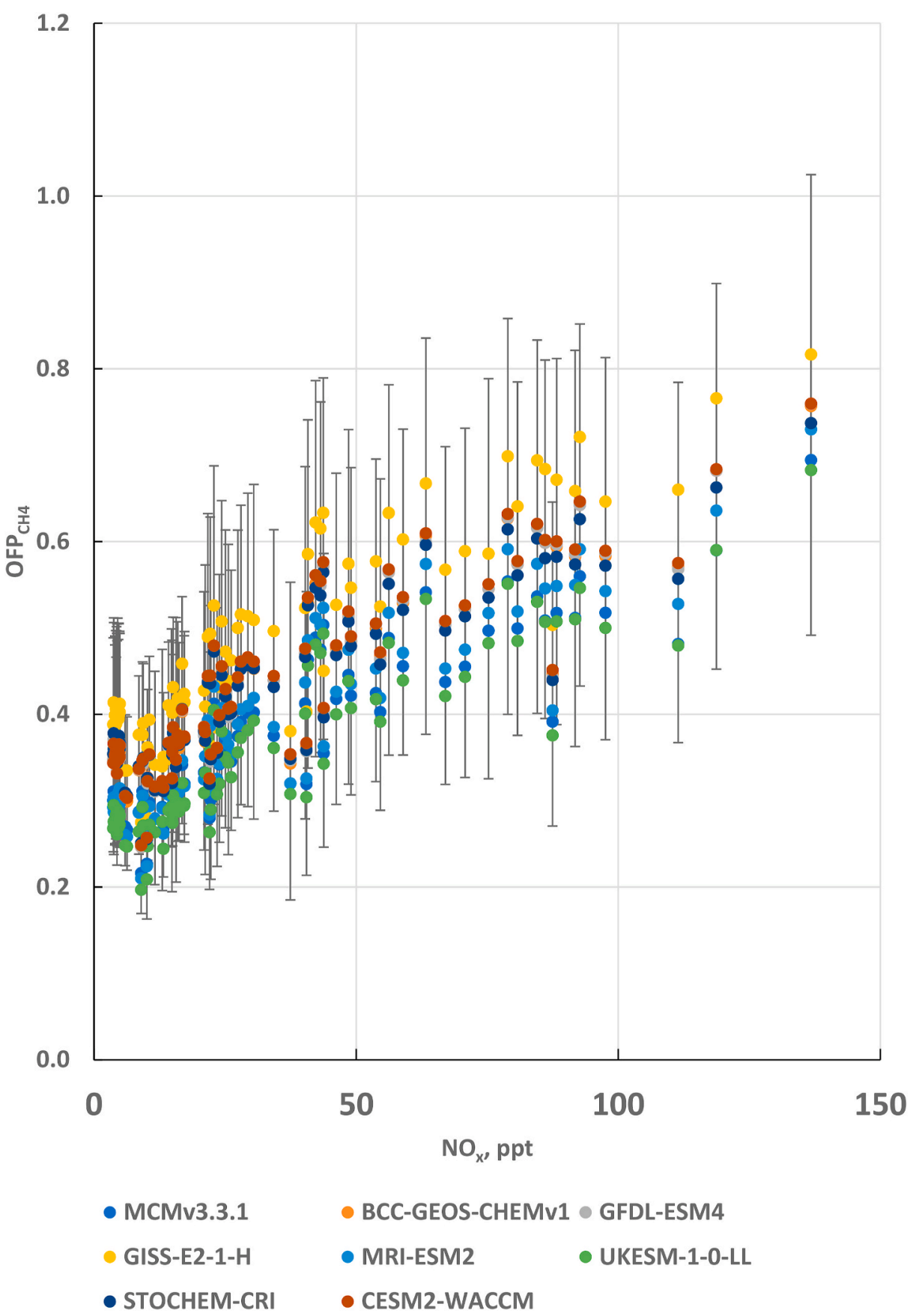

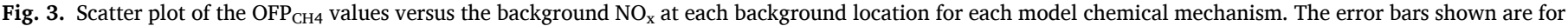
CESM2-WACCM based on the maximum and minimum values found in the Monte Carlo uncertainty analysis.

compensation points, a Monte Carlo uncertainty analysis was performed as described above, using the CESM2-WACCM model mechanism. Here, uncertainties in the fifteen thermal rate coefficients in the $\mathrm{C}_{1}$ chemistry were taken from the JPL (Burkholder et al., 2015) data compilation and those for the three photochemical rate coefficients from our previous Monte Carlo studies (Derwent et al., 2018). The averages, standard deviations and ranges expressed as a fraction of the average $\mathrm{NO}_{\mathrm{x}}$ compensation points were calculated for each of the 90 background locations over the 1000 constrained box model experiments. On average, over the 90 background locations, the range of the Monte Carlo replicates, expressed as a fraction of the average, was $0.50 \pm 0.12$ (where the confidence interval shown is $2-\sigma$ ). Fig. 1 presents a scatter plot of the $\mathrm{NO}_{\mathrm{x}}$ compensation points determined for each background location versus the background $\mathrm{O}_{3}$ mixing ratio for that location. Scatter plots are provided for each model chemical mechanism and the close correlation between the mechanisms is clearly apparent. Also shown are the error bars for CESM2-WACCM calculated in the Monte Carlo uncertainty analysis of the $\mathrm{C}_{1}$ chemical kinetic input data uncertainties. On the basis of this figure, the inter-mechanism ranges of $0.17 \pm 0.12$ are close to a factor of three smaller than the intra-mechanism ranges of $0.50 \pm 0.12$, in the $\mathrm{NO}_{\mathrm{x}}$ compensation points at each location as evaluated by the Monte Carlo uncertainty analysis of the CESM2-WACCM $\mathrm{C}_{1}$ chemical kinetic input uncertainties.

\section{Impacts of organic compounds on $\mathrm{OH}$ radicals}

In this section, the impacts of four organic compounds: $\mathrm{CH}_{4}, \mathrm{C}_{2} \mathrm{H}_{6}$, $\mathrm{CH}_{3} \mathrm{COCH}_{3}$ and $\mathrm{C}_{3} \mathrm{H}_{8}$ on $\mathrm{OH}$ radicals were investigated using the 


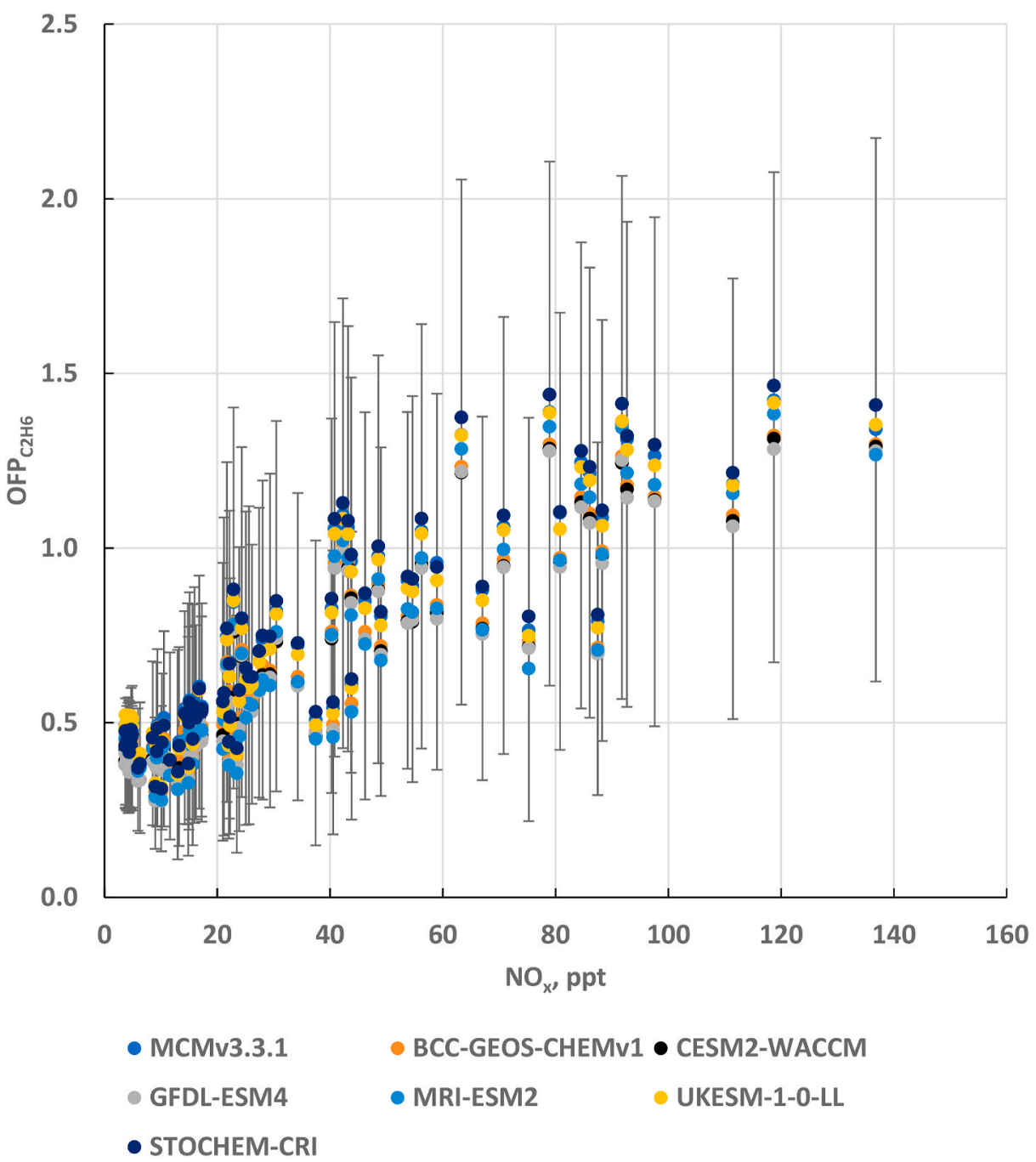

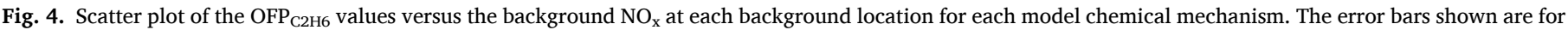
CESM2-WACCM based on the maximum and minimum values found in the Monte Carlo uncertainty analysis.

constrained box model. The experimental details are presented in the Supplementary Information. Small additions of all four compounds led to small depletions in the time-averaged hydroxyl radical number densities $(\underline{\mathrm{OH}})$ in all 90 background locations and with all chemical mechanisms. The hydroxyl responses $(\Delta \mathrm{OH})$ declined linearly with the increases in the rates of oxidation of the organic compound $(\Delta R)$. Scatter plots of $\Delta \underline{\mathrm{OH}}$ versus $\Delta \mathrm{R}$ covering all background locations produced a family of straight lines for each chemical mechanism and each organic compound, as shown in Figs. $\mathrm{S} 2-\mathrm{S} 4$ for $\mathrm{CH}_{4}, \mathrm{C}_{2} \mathrm{H}_{6}$ and $\mathrm{C}_{3} \mathrm{H}_{8}$ as examples. The variations in the slopes of these scatter plots between the different chemical mechanisms and organic compounds reflected the divergences in the representation of $\mathrm{C}_{1}-\mathrm{C}_{3}$ chemistry and its ability to recycle $\mathrm{OH}$ back to $\mathrm{HO}_{2}$ through the different organic peroxy radicals.

Each organic compound addition experiment at a given background location generated a value for the hydroxyl reactivity ratio (HRR), (HRR $=\Delta \mathrm{OH} / \Delta \mathrm{R})$ for a given chemical mechanism. The Supplementary Information describes how a total of 90 (background locations) $\mathrm{x} 8$ (chemical mechanisms) x 4 (organic compounds) HRRs were generated using the constrained box model. Fig. 2, as an example, presents a scatter plot of the HRR $\mathrm{CH}_{4}$ values versus the background temperatures found at each location with the different chemical mechanisms. The close relationship between the HRRs and background temperatures seen in Fig. 2 reflects the important influence of temperature on the relationship between the oxidation rates of the organic compounds and $\mathrm{OH}$ depletion.
HRR $_{\mathrm{CH} 4}$ values vary from $(-12$ to -30$) \times 10^{6}$ molecule $\mathrm{cm}^{-3}$ per ppb $\mathrm{hr}^{-1}$, that is by a factor of 2.5 , with decreasing temperature over a narrow range of $\sim 25 \mathrm{~K}$, see Fig. 2 . This temperature dependence follows from the steep temperature dependences found in the rate coefficients for the $\mathrm{OH}+\mathrm{CH}_{4}$ and $\mathrm{HO}_{2}+\mathrm{O}_{3}$ chemical reactions. Inter-mechanism ranges were estimated at each background location and expressed as a fraction of the average. These fractional ranges were averaged over all the background locations and are presented in Table 4. Fractional intermechanism ranges increased from $0.18 \pm 0.05$ for $\mathrm{HRR}_{\mathrm{CH} 4}$, through ethane and propane, to $0.63 \pm 0.2$ for $\mathrm{HRR}_{\mathrm{CH} 3 \mathrm{COCH} 3}$.

Also shown in Fig. 2 are the results from the Monte Carlo uncertainty analysis of CESM2-WACCM, employing $\mathrm{C}_{1}$ rate coefficient uncertainties taken from the JPL chemical kinetic data evaluation (Burkholder et al., 2015). The error bars show the extent of the maxima and minima found in 1000 Monte Carlo replicates at the 90 background locations with the CESM2-WACCM model mechanism. More negative values of $\mathrm{HRR}_{\mathrm{CH} 4}$ have wider error bars than less negative values. Fractional intra-mechanism ranges in $\mathrm{HRR}_{\mathrm{CH} 4}$ averaged out at $0.53 \pm 0.06$ when expressed as a fraction of the mean value, see Table 4. Intra-mechanism ranges in $\mathrm{HRR}_{\mathrm{CH} 4}$ are close to a factor of three wider than inter-mechanism ranges $(0.18 \pm 0.05)$. Fractional intra-mechanism ranges in $\mathrm{HRR}_{\mathrm{C} 2 \mathrm{H} 6}$ and $\mathrm{HRR}_{\mathrm{C} 3 \mathrm{H} 8}$ were close to a factor of two wider than fractional inter-mechanism ranges, and a factor of 2.6 wider with HRR $_{\mathrm{CH} 3 \mathrm{COCH} 3}$, see Table 4. 


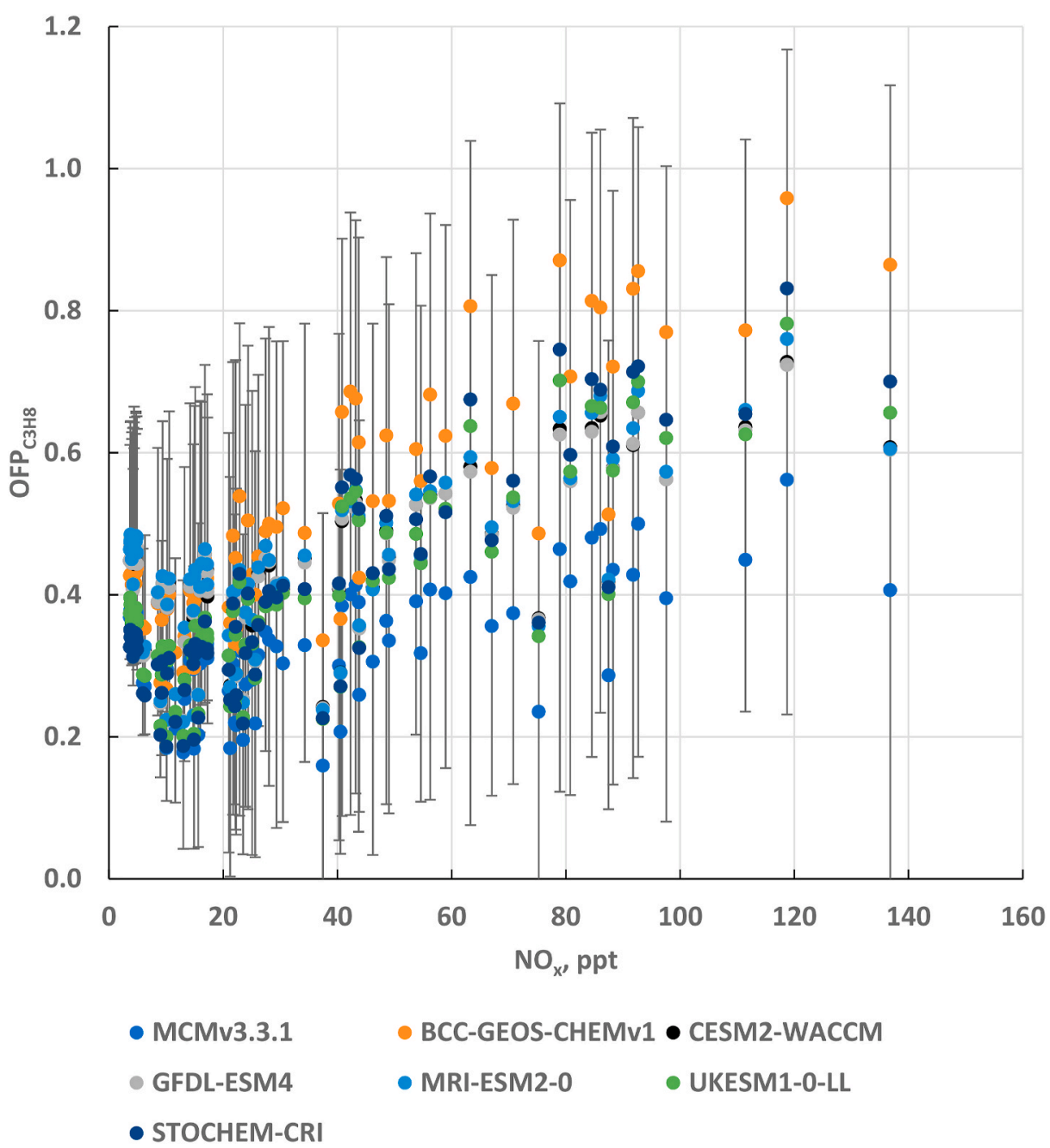

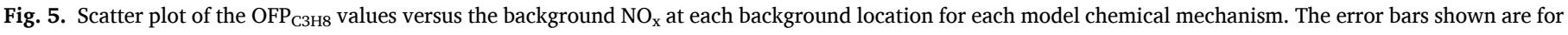
CESM2-WACCM based on the maximum and minimum values found in the Monte Carlo uncertainty analysis.

\section{Impacts of organic compounds on tropospheric ozone}

In this section, the impacts of four organic compounds: $\mathrm{CH}_{4}, \mathrm{C}_{2} \mathrm{H}_{6}$, $\mathrm{CH}_{3} \mathrm{COCH}_{3}$ and $\mathrm{C}_{3} \mathrm{H}_{8}$ on the net production rates of tropospheric $\mathrm{O}_{3}$ were investigated using the constrained box model. The experimental details are presented in the Supplementary Information. Small additions of all four compounds led to small increases in the time-averaged net $\mathrm{O}_{3}$ production rates in all 90 background locations and with all chemical mechanisms. In response to the addition of the four organic compounds, the flux through the organic peroxy $\left(\mathrm{RO}_{2}\right)+$ NO reactions increased and acted as an increased $\mathrm{O}_{3}$ source. This was partially offset by a decrease in the flux through the $\mathrm{HO}_{2}+\mathrm{NO}$ reaction because of the depletion in $\mathrm{OH}$ and $\mathrm{HO} 2$ brought about by the oxidation of the organic compound. However, the decrease in $\mathrm{OH}$ and $\mathrm{HO}_{2}$ also caused decreases in the fluxes through the $\mathrm{O}_{3}$ sink reactions: $\mathrm{OH}+\mathrm{O}_{3}$ and $\mathrm{HO}_{2}+\mathrm{O}_{3}$. Overall, net $\mathrm{O}_{3}$ production (source - sink) increased in response to the addition of the organic compounds at all 90 locations and with all chemical mechanisms.

The responses in the net rate of $\mathrm{O}_{3}$ production, $\Delta$ net $_{\mathrm{O} 3}$ increased with the rate of oxidation of the organic compound $\Delta \mathrm{R}$ as shown by the scatter plots in Figs. S5-S8. OAT sensitivity tests confirmed that all of the differences in the scatter plots between the mechanisms could be accounted for by differences in the reaction rate coefficients and product yields for the $\mathrm{RO}_{2}+\mathrm{HO}_{2}$ and $\mathrm{OH}+\mathrm{ROOH}$ reactions in Tables S1-S3 in the Supplementary Information. The results of each organic compound addition experiment were used to define an $\mathrm{O}_{3}$ formation potential (OFP), such that OFP $=\Delta$ net $_{03} / \Delta \mathrm{R}$, at each of the 90 background locations, with each chemical mechanism and for each organic compound. OFPs were found to increase systematically with increasing background $\mathrm{NO}_{\mathrm{x}}$ as shown in Figs. 3-6. Also shown in each figure are a set of error bars which reflect the range between the maximum and minimum OFPs found at that background location in the Monte Carlo uncertainty analysis of the rate coefficient uncertainties in the $\mathrm{C}_{1}-\mathrm{C}_{3}$ chemistry with the CESM2-WACCM model chemical mechanism. The results presented in Figs. 3-6 are summarised in Table 4.

OFPs were highest for $\mathrm{CH}_{3} \mathrm{COCH}_{3}$ and lowest for $\mathrm{C}_{3} \mathrm{H}_{8}$, with $\mathrm{OFP}_{\mathrm{CH} 3 \mathrm{COCH} 3}>\mathrm{OFP}_{\mathrm{C} 2 \mathrm{H} 6}>\mathrm{OFP}_{\mathrm{CH} 4}>\mathrm{OFP}_{\mathrm{C} 3 \mathrm{H} 8}$. Fractional intermechanism ranges were smallest for $\mathrm{C}_{2} \mathrm{H}_{6}$ and largest for $\mathrm{CH}_{3} \mathrm{COCH}_{3}$ whilst fractional intra-mechanism ranges were smallest for $\mathrm{CH}_{4}$ and largest for $\mathrm{C}_{3} \mathrm{H}_{8}$. Intra-mechanism ranges were nearly seven times wider than inter-mechanism ranges for $\mathrm{C}_{2} \mathrm{H}_{6}$ because mechanism developers had converged on similar descriptions of $\mathrm{C}_{2}$ chemistry, see Table S2, despite there being huge uncertainties in the laboratory determinations of the $\mathrm{C}_{2} \mathrm{H}_{5} \mathrm{O}_{2}+\mathrm{HO}_{2}$ and $\mathrm{OH}+\mathrm{C}_{2} \mathrm{H}_{5} \mathrm{OOH}$ rate coefficients and products yields. Intra-mechanism ranges were 1.5 times wider for $\mathrm{CH}_{4}$, twice as wide for $\mathrm{CH}_{3} \mathrm{COCH}_{3}$ and nearly three times wider for $\mathrm{C}_{3} \mathrm{H}_{8}$.

\section{Discussion and conclusions}

Emissions of organic compounds exert two main impacts on the 


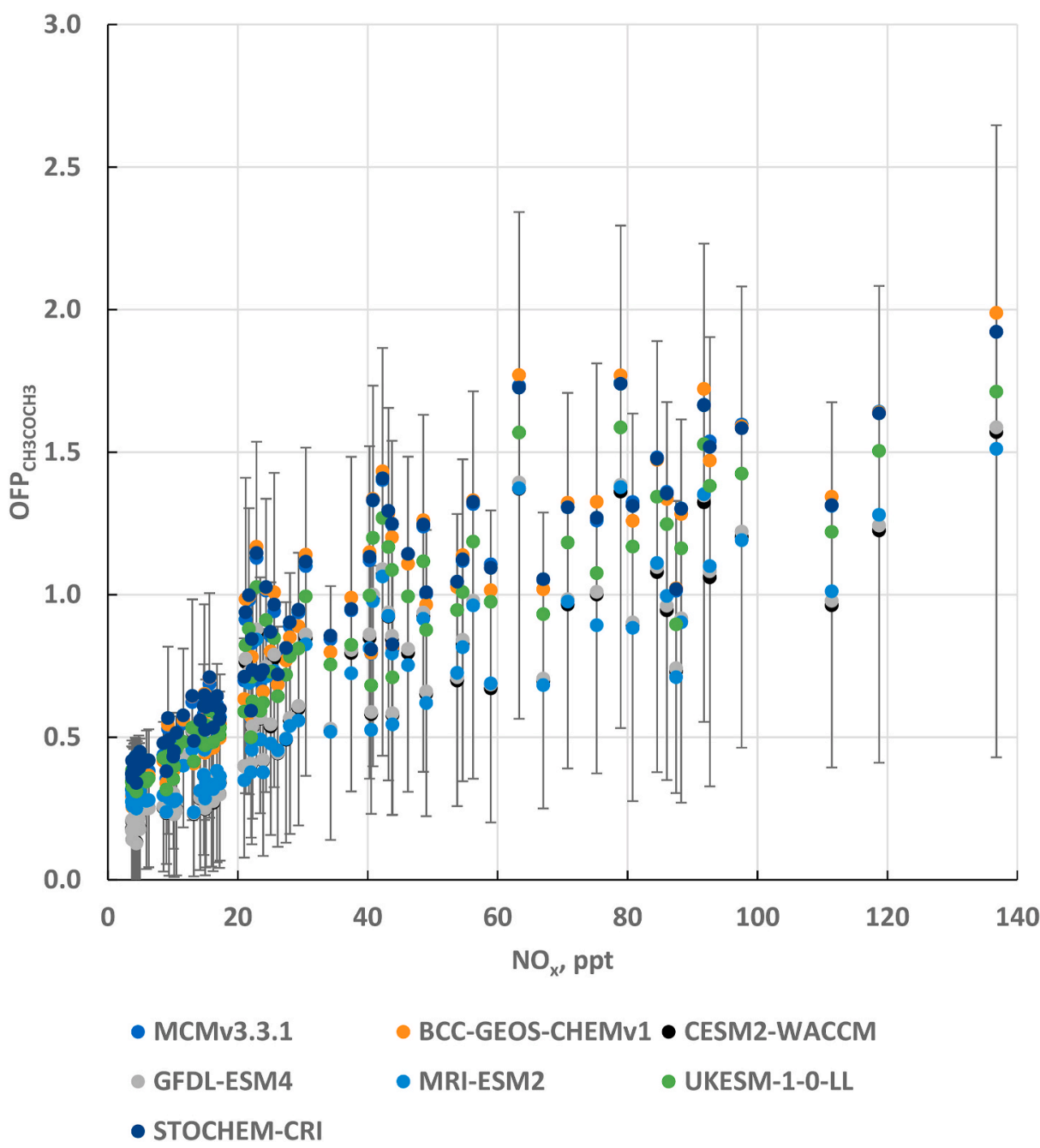

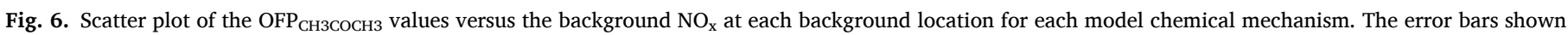
are for CESM2-WACCM based on the maximum and minimum values found in the Monte Carlo uncertainty analysis.

chemistry of the present day and pre-industrial troposphere: depletion of the $\mathrm{OH}$ radical steady state and stimulation of photochemical $\mathrm{O}_{3}$ formation. Depletion of the $\mathrm{OH}$ radical steady state is the driving force behind the $\mathrm{CH}_{4}$ adjustment time (Prather, 2007) and the indirect radiative forcing caused by organic compounds (Collins et al., 2002). OH steady state depletion leads to the decreased efficiency of global $\mathrm{CH}_{4}$ removal and hence increased global burdens of $\mathrm{CH}_{4}$, the second most important contributor to man-made greenhouse gas radiative forcing after $\mathrm{CO}_{2}$. Increased photochemical $\mathrm{O}_{3}$ formation from the oxidation of organic compounds also leads to indirect radiative forcing because tropospheric $\mathrm{O}_{3}$ is the third most important contributor to man-made greenhouse gas radiative forcing after $\mathrm{CO}_{2}$ and $\mathrm{CH}_{4}$. These two impacts of organic compounds have been examined using a constrained box model and form the subject of this earth system model intercomparison.

Addition of four organic compounds: $\mathrm{CH}_{4}, \mathrm{C}_{2} \mathrm{H}_{6}, \mathrm{CH}_{3} \mathrm{COCH}_{3}$ and $\mathrm{C}_{3} \mathrm{H}_{8}$, into the constrained box model representing the pre-industrial troposphere, resulted in depletion of $\mathrm{OH}$ across all 90 background locations and with all chemical mechanisms. A hydroxyl radical reactivity index (HRR) has been defined for each organic species from the ratio of the depletion in $\mathrm{OH}$ to the rate of oxidation of the organic compound at each location and with each chemical mechanism. Table 4 presents a comparison of the mean HRRs for each chemical mechanism. HRRs were stronger (greater depletion) for the alkanes and weaker for $\mathrm{CH}_{3} \mathrm{COCH}_{3}$. Inter-mechanism uncertainties in the HRRs were quantified in Table 4 using inter-mechanism ranges expressed as a fraction of the intermechanism average. On this basis, uncertainties were largest $(0.63 \pm$ $0.2)$ for $\mathrm{CH}_{3} \mathrm{COCH}_{3}$ and least for $\mathrm{CH}_{4}(0.18 \pm 0.05)$.

One-at-a-time (OAT) sensitivity studies confirmed that two sets of reactions accounted for the divergences noted in Table 4 in the HRRs between the different chemical mechanisms, namely, $\mathrm{OH}+\mathrm{ROOH}$ (in particular, $\mathrm{OH}+\mathrm{CH}_{3} \mathrm{OOH}$ ) and $\mathrm{RO}_{2}+\mathrm{HO}_{2}$ (in particular, $\mathrm{CH}_{3} \mathrm{O}_{2}+$ $\mathrm{HO}_{2}$ ). The divergences found in the HRRs in Table 4 stem directly from the choices made by the mechanism developers for chemical kinetic data for $\mathrm{C}_{1}-\mathrm{C}_{3}$ chemistry. The evaluated chemical kinetic data evaluations offer little coverage of $\mathrm{C}_{3}$ chemistry and hence differences in its representation in chemical mechanisms are unavoidable for $\mathrm{CH}_{3} \mathrm{COCH}_{3}$ and $\mathrm{C}_{3} \mathrm{H}_{8}$. This situation inevitably leads to the increased ranges in the HRRs presented in Table 4.

The inter-mechanism ranges in Table 4 are driven by the choices made by mechanism developers for some key rate coefficients and product yields and these ultimately lead back to the differences in the evaluations between the two major chemical kinetic data compilations, JPL (Burkholder et al., 2015) and IUPAC (Ammann et al., 2013). However, both evaluations point to the large uncertainties present in the laboratory determinations of rate coefficients and product channel branching ratios for some key $\mathrm{RO}_{2}+\mathrm{HO}_{2}$ and $\mathrm{OH}+\mathrm{ROOH}$ reactions. Indeed, IUPAC (Amman et al., 2013) comment that the reported values for $\mathrm{HO}_{2}+\mathrm{C}_{2} \mathrm{H}_{5} \mathrm{O}_{2}$ at $298 \mathrm{~K}$ show a level of disagreement covering almost a factor of three. It is these uncertainties that drive the 
intra-mechanism ranges found with the Monte Carlo uncertainty analysis carried out with the CESM2-WACCM model chemical mechanism. Generally speaking, intra-mechanism ranges in the HRRs in Table 4 were much larger than the inter-mechanism ranges. Therefore, our conclusions concerning the uncertainties in HRRs focus directly on the inadequacy of the literature chemical kinetic database rather than on the apparent divergences between the IUPAC (Amman et al., 2013) and JPL (Burkholder et al., 2015) chemical kinetic data evaluations. It is not surprising that these two evaluations diverge, bearing in mind the large uncertainties that exist surrounding $\mathrm{RO}_{2}+\mathrm{HO}_{2}$ and $\mathrm{OH}+\mathrm{ROOH}$ rate coefficients and product channel branching ratios. Inter-model ranges are therefore likely to provide a gross underestimation of the real uncertainties in earth system model predictions of the time evolution in tropospheric $\mathrm{CH}_{4}$ levels from pre-industrial times through to the present day.

Earth system models also have an important climate policy support role through their ability to describe the growth in tropospheric $\mathrm{O}_{3}$ levels since pre-industrial times, since this allows the direct quantification of the contribution to radiative forcing from tropospheric $\mathrm{O}_{3}$. A major determinant of this growth is the rise in global $\mathrm{NO}_{\mathrm{x}}$ emissions since this controls the spatial distribution of $\mathrm{O}_{3}$ source regions at any point in time between pre-industrial times and the present day. The point at which tropospheric chemistry turns from being an $\mathrm{O}_{3}$ sink to an $\mathrm{O}_{3}$ source with increasing $\mathrm{NO}_{\mathrm{x}}$ levels is termed the $\mathrm{NO}_{\mathrm{x}}$ compensation point and these have been determined for each chemical mechanism and each background location with the constrained box model for preindustrial conditions. Compensation points increased from about $9 \mathrm{ppt}$ to close to $70 \mathrm{ppt}$ as background $\mathrm{O}_{3}$ levels increased from $7 \mathrm{ppb}$ to 21 ppb. The inter-mechanism uncertainty range averaged $0.17 \pm 0.12$ and was largely driven by the choice of rate coefficients and product yields for the $\mathrm{OH}+\mathrm{CH}_{3} \mathrm{OOH}$ and $\mathrm{HO}_{2}+\mathrm{CH}_{3} \mathrm{O}_{2}$ reactions. The intramechanism uncertainty range from the Monte Carlo uncertainty analysis of the CESM2-WACCM model chemistry was found to be $0.50 \pm$ 0.12. This is close to a factor of three wider than the inter-mechanism range.

Compensation points quantify the $\mathrm{NO}_{\mathrm{x}}$ conditions where $\mathrm{O}_{3}$ sources and sinks balance but $\mathrm{O}_{3}$ productivities quantify the intensity of net $\mathrm{O}_{3}$ production in a given source region. Table 4 presents the ozone formation potentials (OFPs) for $\mathrm{CH}_{4}, \mathrm{C}_{2} \mathrm{H}_{6}, \mathrm{CH}_{3} \mathrm{COCH}_{3}$ and $\mathrm{C}_{3} \mathrm{H}_{8}$ as determined from the scatter plots in Figs. 3-6. OFPs are largest for $\mathrm{C}_{2} \mathrm{H}_{6}$ and $\mathrm{CH}_{3} \mathrm{COCH}_{3}$ and smallest for $\mathrm{CH}_{4}$ and $\mathrm{C}_{3} \mathrm{H}_{8}$. Inter-mechanism ranges in the OFPs in Table 4 were highest for $\mathrm{CH}_{3} \mathrm{COCH}_{3}$ and $\mathrm{C}_{3} \mathrm{H}_{8}$ because of the increased complexity of $\mathrm{C}_{3}$ chemistry and were least for $\mathrm{C}_{2} \mathrm{H}_{6}$. In all cases, the intra-mechanism ranges from the Monte Carlo uncertainty analyses were significantly wider than the inter-mechanism ranges. This was particularly noticeable for $\mathrm{C}_{2} \mathrm{H}_{6}$ where the intra-mechanism range was more than six times wider than the inter-mechanism range. Similarly, a factor of three was apparent for $\mathrm{C}_{3} \mathrm{H}_{8}$. The inter-mechanism ranges were therefore a poor guide to the real uncertainties in OFPs because there was little divergence in the chosen values of rate coefficients for the $\mathrm{RO}_{2}+\mathrm{HO}_{2}$ and $\mathrm{OH}+\mathrm{ROOH}$ reactions, despite the huge uncertainties in these rate coefficients. This real level of uncertainty only became apparent in the Monte Carlo uncertainty analyses.

Solazzo and Galmarini (2015) offer a careful consideration of ensembles of opportunity, which is evidently the situation here, where six earth system models from the CMIP6 study have been intercompared alongside two other chemical mechanisms. Solazzo and Galmarini (2015) point out that simply averaging model simulations may provide an illusory estimate of model uncertainty. Inter-mechanism ranges found here for HRRs and OFPs are all significantly smaller than real uncertainty ranges found from Monte Carlo uncertainty analyses. The results found here for the OFP for ethane are a classic example of one of the pitfalls of ensembles of opportunity identified by Solazzo and Galmarini (2015). The processes of standardisation and coordination have led model developers to use common rate coefficients and product channel branching ratios for $\mathrm{RO}_{2}+\mathrm{HO}_{2}$ and $\mathrm{OH}+\mathrm{ROOH}$ reactions and so have hid real uncertainties. Inter-mechanism ranges, therefore, are unlikely to reflect true uncertainties.

Further work will be required to understand whether the uncertainties found here persist into earth system model predictions of the growth in $\mathrm{CH}_{4}$ and tropospheric $\mathrm{O}_{3}$ levels between pre-industrial times and the present day. It is tempting to offer an explanation for the differences seen in pre-industrial $\mathrm{O}_{3}$ in the six ESMs that took part in CMIP6 (Eyring et al., 2016) in terms of the differences found here. GISS-E2-1-H, for example, exhibited the lowest average $\mathrm{NO}_{\mathrm{x}}$ compensation point and the lowest pre-industrial annual mean at Cape Grim, Tasmania whilst UKESM1-0-LL exhibited the highest on both counts. In which case, it is possible that inter-mechanism ranges in CMIP6 underestimate real uncertainties in pre-industrial $\mathrm{O}_{3}$ predictions by a wide margin. Real uncertainties are unlikely to be revealed by multi-model comparisons because model developers use common assumptions when input data are highly uncertain as shown here with the $\mathrm{RO}_{2}+\mathrm{HO}_{2}$ and $\mathrm{OH}+$ $\mathrm{ROOH}$ rate coefficients and product channel branching ratios. Further definitive laboratory studies are required for more accurately defining the reaction rates and product yields of the reactions of the simple peroxy radicals, between themselves and with $\mathrm{HO}_{2}$ and of the fates and behaviour of the simple hydroperoxides. Such future studies should aim to reduce the uncertainties in key reaction rate coefficients and determine whether they contribute significantly to the uncertainties in earth system model projections since pre-industrial times of $\mathrm{CH}_{4}$ and $\mathrm{O}_{3}$ and hence to the radiative forcing of climate change.

\section{CRediT authorship contribution statement}

Richard G. Derwent: Conceptualization, Investigation, Writing original draft, Methodology, Writing - review \& editing. David D. Parrish: Conceptualization, Writing - original draft, Methodology, Writing - review \& editing. Alex T. Archibald: Data provision, Discussion of data, Writing - review \& editing. Makoto Deushi: Data provision, Discussion of data, Writing - review \& editing. Susanne E. Bauer: Data provision, Discussion of data, Writing - review \& editing. Kostas Tsigaridis: Data provision, Discussion of data, Writing - review \& editing. Drew Shindell: Data provision, Discussion of data, Writing review \& editing. Larry W. Horowitz: Data provision, Discussion of data, Writing - review \& editing. M. Anwar H. Khan: Data provision, Discussion of data, Writing - review \& editing. Dudley E. Shallcross: Data provision, Discussion of data, Writing - review \& editing.

\section{Declaration of competing interest}

The authors declare that they have no known competing financial interests or personal relationships that could have appeared to influence the work reported in this paper.

\section{Acknowledgements}

RGD wishes to thank the Earth System Modelling teams for providing access to their chemical mechanisms. MD was partly supported by JSPS KAKENHI grant no. JP19K12312. DES and MAHK thank NERC (Grant code-NE/K004905/1), Bristol ChemLabS and Primary Science Teaching Trust under whose auspices various aspects of this work using STOCHEM-CRI were supported. DS thanks NASA GISS and MAP for funding. Help from Louisa Emmons, John Orlando and Geoff Tyndall for providing and developing the MOZART family of chemical mechanisms is gratefully acknowledged. RGD acknowledges help from Michael Jenkin with the implementation of the MCMv3.3.1 and CRIv2.2 chemical mechanisms and from Mat Evans with the implementation of GEOSCHEM. ATA would like to thank the Met Office and NCAS for funding for the development of the UKCA model through the auspices of the Joint Weather and Climate Research Programme. SET and KT acknowledge NASA MAP for funding. GISS-E2-1-H resources supporting this work were provided by the NASA High-End Computing (HEC) Programme 
through the Center for Climate Simulation (NCSS) at Goddard Space Flight Center.

\section{Appendix A. Supplementary data}

Supplementary data to this article can be found online at https://doi. org/10.1016/j.atmosenv.2021.118248.

\section{References}

Ammann, M., Cox, R.A., Jenkin, M.E., Melhouki, A., Rossi, M.J., Troe, J., Wallington, T. J., 2013. Evaluated kinetic and photochemical data for atmospheric chemistry: volume VI - heterogeneous reactions with liquid substrates. Atmos. Chem. Phys. 13, 8045-8228.

Archibald, A.T., O'Connor, F.M., Abrahm, N.L., Archer-Nicholls, S., Chipperfield, M.P., Dalvi, M., Folberth, G.A., Dennison, F., Dhomse, S.S., Griffiths, P.T., Hardacre, C., Hewitt, A.J., Hill, S.R., Johnson, C.E., Keeble, J., Kohler, M.O., Morgenstern, O., Mulcahy, J.P., Ordonez, C., Pope, R.J., Rumbold, S.T., Russo, M.R., Savage, N.H., Sellar, A., Stringer, M., Turnock, S.T., Wild, O., Zeng, G., 2020a. Description and evaluation of the UKCA stratosphere-troposphere chemistry scheme (StratTrop vv 1.0) implemented in UKESM1. Geosci. Model Dev. (GMD) 13, 1223-1266.

Archibald, A.T., Neu, J.L., Elshorbany, Y., Cooper, O.R., Young, P.J., Akiyoshi $<$ H, Cox, R.A., Coyle, M., Derwent, R.G., Deushi, M., Finco, A., Frost, G.J., Galbally, I.E., Gerosa, G., Granier, C., Griffiths, P.T., Hossani, R., Hu, L., Jockel, P., Josse, B., Lin, M.Y., Mertens, M., Morgenstern, O., Naja, M., Naik, V., Saiz-Lopez, A., Saxena, P., Shin, Y.M., Shaahid, I., Shallcross, D.E., Tilnes, S., Wallington, T.J., TRickel, T., Wang, T., Worden, H.M., Zeng, G., 2020b. Tropospheric Ozone Assessment Report: Critical Review of Changes in the Tropospheric Ozone Burden and Budget from 1960 - 2100. Elementa: Science of the Anthropocene.

Burkholder, J.B., Sander, S.P., Abbatt, J., Barker, J.R., Huie, R.E., Kolb, C.E., Kurylo, M. J., Orkin, V.L., Wilmouth, D.M., Wine, P.H., 2015. Chemical Kinetics and Photochemical Data for Use in Atmospheric Studies. Evaluation No. 18. JPL Publication 15-10. Jet Propulsion Laboratory, Pasadena. http://jpleval.jpl.nasa.gov.

Calvert, J.G., Derwent, R.G., Orlando, J.J., Tyndall, G.S., Wallington, T.J., 2008. Mechanisms of Atmospheric Oxidation of the Alkanes. Oxford University Press, Oxford, UK.

Collins, W.J., Derwent, R.G., Johnson, C.E., Stevenson, D.S., 2002. The oxidation of organic compounds in the troposphere and their global warming potentials. Climatic Change 52, 453-47.

Crutzen, P.J., 1974. Photochemical reactions initiated by and influencing ozone in the polluted troposphere. Tellus 26, 47-57.

Curtis, A.R., Sweetenham, W.P., 1987. FACSIMILE Release H User's Manual. AERE Report R11771. H.M. Stationery Office, London.

Derwent, R., 2017. Intercomparison of chemical mechanisms for air quality policy formulation and assessment under North American conditions. J. Air Waste Manag. Assoc. 67, 789-796.

Derwent, R.G., 2020. Representing organic compound oxidation in chemical mechanisms for policy-relevant air quality models under background troposphere conditions. Atmosphere 11, 171. https://doi.org/10.3390/atmos11020171.

Derwent, R.G., Witham, C.S., Utembe, S.R., Jenkin, M.E., Passant, N.R., 2010. Ozone in Central England: the impact of 20 years of precursor emission controls in Europe. Environ. Sci. Pol. 13, 195-204.

Derwent, R.G., Utembe, S.R., Jenkin, M.E., Shallcross, D.E., 2015. Tropospheric ozone production regions and the intercontinental origins of surface ozone. Atmos. Environ. 112, 216-224.

Dunne, J.P., Horowitz, L.W., Adcroft, A.J., Ginoux, P., Held, I.M., John, J.G., Krasting, J. P., Malyshev, S., Naik, V., Paulot, F., Shevliakova, E., Stock, C.A., Zadeh, N., Balaji, V., Blanton, C., Dunne, K.A., Dupuis, C., Durachta, J., Dussin, R., Gauthier, P. P.G., Griffies M., S., Guo, H., Hallberg, R.W., Harrison, M., He, J., Hurlin, W., McHugh, C., Menzel, R., Milly, P.C.D., Nikonov, S., Paynter, D.J., Ploshay, J., Radhakrishnan, A., Rand, K., Reichl, B.G., Robinson, T., Schwarzkopf, M.D., Sentman, L.A., Underwood, S., Vahlenkamp, H., Winton, M., Wittenberg, A.T., Wyman, B., Zeng, Y., Zhao, M., 2020. The GFDL Earth System Model version 4.1 (GFDL-ESM4.1): Overall coupled model description and simulation characteristics. J. Adv. Model. Earth Syst. 12, e2019MS002015.

Emmerson, K.M., Evans, M.J., 2009. Comparison of tropospheric gas-phase chemistry schemes for use within global models. Atmos. Chem. Phys. 9, 1831-1845.

Emmons, L.K., Walters, S., Hess, P.G., Lamarque, J.-F., Pfister, G.G., Fillmore, D., Granier, C., Guenther, A., Kinnison, D., Laepple, T., Orlando, J., Tie, X., Tyndall, G., Wiedinmyer, C., Baughcum, S.L., Kloster, S., 2010. Description and evaluation of the model for ozone and related chemical tracers, vesion 4 (MOZART-4). Geosci. Model Dev. (GMD) 3, 43-67.

Emmons, L.K., Schwantes, R.H., Orlando, J.J., Tyndall, G., Kinnison, D., Lamarque, J.-F., Marsh, D., Mills, M.J., Tilmes, S., Bardeen, C., Buchholz, R.R., Conley, A., Gettelman, A., Garcia, R., Simpson, I., Blake, D.R., Meinardi, S., Petron, G., 2020. The chemistry mechanism in the community earth system model version 2 (CESM2). J. Adv. Model. Earth Syst. 12 e2019MS001882. https://doi.org/10.1029/201 9MS001882.

ENVIRON, 2015. Appendix C, CAMx User's Guide Version 6.2. Environ International Corporation, Novato, California. March 2015.

Etheridge, D.M., Pearman, G.I., Fraser, P.J., 1992. Changes in tropospheric methane between 1841 and 1978 from a high accumulation-rate Antarctic ice core. Tellus B 44, 282-294.
Eyring, V., Bony, S., Meehl, G.A., Senior, C.A., Stevens, B., Stouffer, Taylor, K.E., 2016. Overview of the coupled model intercomparison Project phase 6 (CMIP6) experimental design and organization. Geosci. Model Dev. (GMD) 9, 1937-1958.

Gettelman, A., Mills, M.J., Kinnison, D.E., Garcia, R.R., Smith, A.K., Marsh, D.R., et al., 2019. The whole atmosphere community climate model version 6 (WACCM6). Journal of Geophysical Research Atmospheres. https://doi.org/10.1029/ 2019JD030943.

Hall, S.R., Ullmann, K.R., Prather, M.J., Flynn, C.M., Murray, L.T., Fiore, A.M., Correa, G., Stode, S.A., Steenrod, S.D., Lamarque, J.-F., Guth, J., Josse, B., Flemming, J., Huijnen, V., Abraham, N.L., Archibald, A.T., 2018. Cloud impacts on photochemistry: building a climatology of photolysis rates from the Atmospheric Tomography mission. Atmos. Chem. Phys. 18, 16809-16828.

IPCC, 1990. Climate Change: the IPCC Scientific Assessment (1990). Cambridge University Press, Cambridge, UK.

IPCC, 1996. Climate Change 1995: the Science of Climate Change. Cambridge University Press, Cambridge, UK.

IPCC, 2001. Climate Change 2001: the Scientific Basis. Cambridge University Press, Cambridge, UK.

IPCC, 2013. Climate Change 2013: the Physical Science Basis. Cambridge University Press, Cambridge, UK.

Jenkin, M.E., Khan, M.A.H., Shallcross, D.E., Bergstrom, R., Simpson, D., Murphy, K.L.C., Rickard, A.R., 2019. Atmos. Environ. 212, 172-182.

Jenkin, M.E., Young, J.C., Rickard, A.R., 2015. The MCM v3.3.1 degradation scheme for isoprene. Atmos. Chem. Phys. 15, 11433-11459.

Kelley, M., Schmidt, G.A., Nazarenko, L., Bauer, S.E., Ruedy, R., Russell, G.L., Ackerman, A.S., Aleinov, I., Bauer, M., Bleck, R., et al., 2020. GISS-E2.1: configurations and climatology. J. Adv. Model. Earth Syst. https://doi.org/10.1029/ 2019MS002025.

Khalil, M.A.K., Rasmussen, R.A., 1988. Nitrous oxide: trends and global mass balance over the last 3000 years. Ann. Glaciol. 10, 73-79.

Khan, M.A.H., Miles, B., Jenkin, M.E., Derwent, R.G., Percival, C.J., Shallcross, D.E., 2020. Investigating the impacts of non-acyl peroxy nitrates on the global composition of the troposphere using a 3-D chemical transport model, STOCHEMCRI. American Chemical Society Earth and Space Chemistry 4, 1201-1212.

Khan, M.A.H., Schlich, B.-L., Jenkin, M.E., Cooke, M.C., Derwent, R.G., Neu, J.L., Percival, C.J., Shallcross, D.E., 2021. Changes to simulated global atmospheric composition resulting from recent revisions to isoprene oxidation chemistry. Atmos. Environ. 244, 117914.

Levy, H., 1972. Photochemistry of the lower troposphere. Planet. Space Sci. 20, 919-935.

Monks, P.S., Archibald, A.T., Colette, A., Cooper, O., Coyle, M., Derwent, R., Fowler, D., Granier, C., Law, K.S., Mills, G.E., Stevenson, D.S., Tarasova, O., Thouret, V., von Schneidemesser, E., Sommariva, R., Wild, O., Williams, M.L., 2015. Tropospheric ozone and its precursors from the urban to the global scale from air quality to shortlived climate forcer. Atmos. Chem. Phys. 15, 8889-8973.

Newsome, B., Evans, M., 2017. Impact of uncertainties in inorganic chemical rate constants on tropospheric composition and ozone radiative forcing. Atmos. Chem. Phys. 17, 14333-14352.

Prather, M.J., 2007. Lifetimes and time scales in atmospheric chemistry. Philosophical Transactions of the Royal Society A 365, 1705-1726.

Raynaud, D., Barnola, 1985. An Antarctic ice core reveals atmospheric $\mathrm{CO}_{2}$ variations over the past few centuries. Nature 315, 309-311.

Revell, L.E., Stenke, A., Tummon, F., Feinberg, A., Rozanov, E., Peter, T., Abraham, N.L., Akiyoshi, H., Archibald, A.T., Butchart, N., Deushi, M., Jockel, P., Kinnison, D., Michou, M., Morgenstern, O., O'Connor, F.M., Oman, L.D., Pitari, G., Plummer, D.A., Schofield, R., Stone, K., Tilmes, S., Visioni, D., Yamahita, Y., Zeng, G., 2018. Tropospheric ozone in CCMI models and Gaussian process emulation to understand biases in the SOCOLv3 chemistry-climate model. Atmos. Chem. Phys. 18, $16155-16172$

Sellar, A.A., Jones, C.G., Mulcahy, J., Tang, Y., Yool, A., Wiltshire, A., O'Connor, F.M., Stringer, M., Hill, R., Palmieri, J., Woodward, S., Mora, L., Kuhlbrodt, T., Rumbold, S., Kelley, D.I., Ellis, R., Johnson, C.E., Walton, J., Abraham, N.L., Andrews, M.B., Andrews, T., Archibald, A.T., Berthou, S., Burke, E., Blockley, E., Carslaw, K., Dalvi, M., Edwards, J., Folberth, G.A., Gedney, N., Griffiths, P.T., Harper, A.B., Hendry, M.A., Hewitt, A.J., Johnson, B., Jones, A., Jones, C.D., Keeble, J., Liddicoat, S., Morgenstern, O., Parker, R.J., Predoi, V., Robertson, E., Siahaan, A., Smith, R.S., Swaminathan, R., Woodhouse, M.T., Zeng, G., Zerroukat, M., 2019. UKESM1: description and evaluation of the UK earth system model. J. Adv. Model. Earth Syst., 2019MS001739 https://doi.org/10.1029/ 2019MS001739.

Solazzo, E., Galmarini, S., 2015. A science-based use of ensembles of opportunities for assessment and scenario studies. Atmos. Chem. Phys. 15, 2535-2544.

Tilmes, S., Hodzic, A., Emmons, L.K., Mills, M.J., Gettelman, A., Kinnison, D.E., Park, M., Lamarque, J.-F., Vitt, F., Shrivastava, M., Campuzano Jost, P., Jimenez, J., Liu, X., 2019. Climate forcing and trends of organic aerosols in the community earth system model (CESM2). J. Adv. Model. Earth Syst., 2019MS001827 https://doi.org/ 10.1029/2019MS001827.

Utembe, S.R., et al., 2010. Using a reduced Common Representative Intermediates (CRIv2-R5) mechanism to simulate tropospheric ozone in a 3-D Lagrangian chemistry transport model. Atmos. Environ. 44, 1609-1622.

Wang, Y., Jacob, D.J., 1998. Anthropogenic forcing on tropospheric ozone and OH since preindustrial times. J. Geophys. Res. 103 (31), 123-131, 136.

Wild, O., Voulgarakis, A., O’Connor, F., Lamarque, J.-F., Ryan, E.M., Lee, L., 2020. Global sensitivity analysis of chemistry-climate model budgets of tropospheric ozone and OH: exploring model diversity. Atmos. Chem. Phys. 20, 4047-4058.

Wu, T., Lu, Y., Fang, Y., Xin, X., Li, L., Li, W., Jie, W., Zhang, J., Liu, Y., Zhang, L., Zhang, F., Zhang, Y., Wu, F., Li, J., Chu, M., Wang, Z., Shi, X., Liu, X., Wei, M., 
Huang, A., Zhang, Y., Liu, X., 2019. The beijing climate center climate system model (BCC-csm): the main progress from CMIP5 to CMIP6. Geosci. Model Dev. (GMD) 12, 1573-1600. https://doi.org/10.5194/gmd-12-1573-2019,2019.552.

Wu, T., Zhang, F., Zhang, J., Jie, W., Zhang, Y., Wu, F., Li, L., Yan, J., Liu, X., Lu, X., Tan, H., Zhang, L., Wang, J., Hu, A., 2020. Beijing climate center earth system model version 1 (BCC-ESM1): model description and evaluation of aerosol simulations. Geosci. Model Dev. (GMD) 13, 977-1005. https://doi.org/10.5194/gmd-13-9772020.
Young, P.J., et al., 2018. Tropospheric ozone assessment report: assessment of globalscale model performance for global and regional ozone distributions, variability and trends. Elementa Science of the Anthropocene 6, 10. https://doi.org/10.1525/eleme nta.265.

Yukimoto, S., Kawai, H., Koshiro, T , Oshima, N., Yoshida, K., Urakawa, S., Tsujino, H. Deushi, M., Tanaka, T., Hosaka, M., Yabu, S., Yoshimura, H., Shindo, E., Mizuta, R., Obata, A., Adachi, Y., Ishii, M., 2019. The meteorological Research institute earth system model version 2.0, MRI-esm2.0: description and basic evaluation of the physical component. J. Meteorol. Soc. Jpn. 97, 931-965. 